\title{
The excitation-contraction coupling mechanism in skeletal muscle
}

\author{
Juan C. Calderón • Pura Bolaños • Carlo Caputo
}

Received: 1 August 2013 /Accepted: 6 December 2013 /Published online: 24 January 2014

(C) International Union for Pure and Applied Biophysics (IUPAB) and Springer-Verlag Berlin Heidelberg 2014

\begin{abstract}
First coined by Alexander Sandow in 1952, the term excitation-contraction coupling (ECC) describes the rapid communication between electrical events occurring in the plasma membrane of skeletal muscle fibres and $\mathrm{Ca}^{2+}$ release from the SR, which leads to contraction. The sequence of events in twitch skeletal muscle involves: (1) initiation and propagation of an action potential along the plasma membrane, (2) spread of the potential throughout the transverse tubule system (T-tubule system), (3) dihydropyridine receptors (DHPR)-mediated detection of changes in membrane potential, (4) allosteric interaction between DHPR and sarcoplasmic reticulum (SR) ryanodine receptors (RyR), (5) release of $\mathrm{Ca}^{2+}$ from the SR and transient increase of $\mathrm{Ca}^{2+}$ concentration in the myoplasm, (6) activation of the myoplasmic $\mathrm{Ca}^{2+}$ buffering system and the contractile apparatus, followed by (7) $\mathrm{Ca}^{2+}$ disappearance from the myoplasm mediated mainly by its reuptake by the SR through the $\mathrm{SR} \mathrm{Ca}^{2+}$ adenosine triphosphatase (SERCA), and under several conditions movement to the mitochondria and extrusion by the $\mathrm{Na}^{+} / \mathrm{Ca}^{2+}$ exchanger (NCX). In this text, we review the basics of ECC in skeletal muscle and the techniques used to study it. Moreover,
\end{abstract}

Special Issue Advances in Biophysics in Latin America

J. C. Calderón

Physiology and Biochemistry Research Group-Physis, Department of Physiology and Biochemistry, Faculty of Medicine, University of Antioquia UdeA, Calle 70 No 52-21, Medellín, Colombia

J. C. Calderón $\cdot$ P. Bolaños $\cdot$ C. Caputo

Laboratory of Cellular Physiology, Centre of Biophysics and

Biochemistry, Venezuelan Institute for Scientific Research (IVIC),

Caracas, Venezuela

J. C. Calderón $(\square)$

Departamento de Fisiología y Bioquímica, Grupo de Investigación en Fisiología y Bioquímica-Physis, Facultad de Medicina, Universidad de Antioquia, Calle 70 No 52-21, Medellín, Colombia e-mail: jcalderonv00@yahoo.com we highlight some recent advances and point out gaps in knowledge on particular issues related to ECC such as (1) DHPR-RyR molecular interaction, (2) differences regarding fibre types, (3) its alteration during muscle fatigue, (4) the role of mitochondria and store-operated $\mathrm{Ca}^{2+}$ entry in the general ECC sequence, (5) contractile potentiators, and (6) $\mathrm{Ca}^{2+}$ sparks.

Keywords Excitation-contraction coupling $\cdot \mathrm{Ca}^{2+}$ transients . Skeletal muscle $\cdot$ Fibre types $\cdot$ Mitochondria

\section{Introduction}

The excitation-contraction coupling (ECC) phenomenon was defined by Alexander Sandow as the series of events occurring from the generation of the action potential (AP) in the skeletal muscle fibres to the beginning of muscle tension (Kahn and Sandow 1950; Sandow 1952). It has been more than 60 years since his early work on skeletal muscle, during which the temporal and spatial resolution of the techniques to study ECC have greatly improved, reaching a capacity for discrimination at a molecular level. Since then, a great amount of information on ECC morphological basis, physiological importance, and pharmacological modulation, initially in amphibians and more recently in mammalians, has been gathered.

Here, we review the basics of ECC, the techniques used to understand the phenomenon and the most recent advances in ECC knowledge, focused on the information gathered using fast $\mathrm{Ca}^{2+}$ dyes in mammalian preparations and on important issues still under research. These issues include the nature of the interaction among key molecules in ECC, the regulation of the ECC mechanism in different skeletal muscle fibre types, its role in phenomena such as fatigue, its drug modulation, the store-operated $\mathrm{Ca}^{2+}$ entry (SOCE) -mitochondria-ECC relationship and $\mathrm{Ca}^{2+}$ sparks. 


\section{The excitation-contraction coupling (ECC) mechanism in skeletal muscle}

$\mathrm{Ca}^{2+}$ cell homeostasis and signalling result from dynamic interactions between mechanisms that provoke an increase of cytoplasmic free $\mathrm{Ca}^{2+}$ and those that reduce it. In the specific case of striated muscles, contraction and relaxation mechanisms are both regulated by rapid changes in myoplasmic free $\mathrm{Ca}^{2+}$ concentration. Even before knowing the molecular machinery involved in $\mathrm{Ca}^{2+}$ handling, it was shown that $\mathrm{Ca}^{2+}$ was the activator of the contractile mechanism (Heilbrunn and Wiercinsky 1947; Niedergerke 1955; Weber 1959), and that its concentration increase in the myoplasm elicited by electrical stimulation, precedes tension generation (Ridgway and Ashley 1967; Ebashi et al. 1969). It was also known that muscle contraction depends on $\mathrm{Ca}^{2+}$ released from the SR (Caputo and Giménez 1967; Armstrong et al. 1972) and that, after activation, most of the $\mathrm{Ca}^{2+}$ released goes back finally to the SR (Hasselbach and Makinose 1961; Hasselbach 1964; Winegrad 1968).

The ECC phenomenon represents a fast communication between electrical events occurring in the plasma membrane and $\mathrm{Ca}^{2+}$ release from the SR, which leads to muscle contraction. The sequence of events in skeletal twitch muscle fibres involves: (1) initiation and propagation of an AP along the plasma membrane, (2) radial spread of the potential along the transverse tubule system (T-tubule system), (3) dihydropyridine receptors (DHPR, L-type $\mathrm{Ca}^{2+}$ channel $\mathrm{Ca}_{\mathrm{V}} 1.1$ )-mediated detection of changes in membrane potential, (4) allosteric interaction of the DHPR with the sarcoplasmic reticulum (SR) ryanodine receptors (RyR), (5) release of $\mathrm{Ca}^{2+}$ from the SR and transient increase of $\mathrm{Ca}^{2+}$ concentration in the myoplasm, (6) transient activation of the myoplasmic $\mathrm{Ca}^{2+}$ buffering system and the contractile apparatus, followed by (7) disappearance of $\mathrm{Ca}^{2+}$ from the myoplasm mediated by its movement to the mitochondria, its transport by the $\mathrm{Na}^{+} / \mathrm{Ca}^{2+}$ exchanger (NCX) and its final reuptake by the SR through the SR $\mathrm{Ca}^{2+}$ adenosine triphosphatase (SERCA) (Sandow 1952; Caputo 1983; Fill and Copello 2002; Calderón-Vélez and FigueroaGordon 2009).

In twitch skeletal muscle cells, both the differential and selective conductance and the ion distribution across the membrane generate a resting potential of about $-85 \mathrm{mV}$, with the interior of the cell negative compared to the exterior (Horowicz 1961; Luff and Atwood 1972). The acetylcholine neurotransmitter released into the motor plate by the inferior motor neuron acts as an initiator for the AP in muscle fibres causing the transmembrane potential change to reach values of up to $100 \mathrm{mV}$, through voltage-dependent ionic conductance changes (Horowicz 1961; Hodgkin and Huxley 1952; Luff and Atwood 1972). Since the AP is a regulator of ECC, its modifications (see below) may affect the kinetics of muscle contraction (Hodgkin and Horowicz 1960; Sandow et al.
1965). Experimentally, membrane depolarization can be achieved by replacing neurotransmitters with direct electrical stimulation or by increasing the extracellular $\mathrm{K}^{+}$concentration (Hodgkin and Horowicz 1959). Additionally, contractile activation can be induced bypassing the membrane depolarization step, for instance with the help of caffeine (Axelsson and Thesleff 1958; Endo 1975).

The plasma membrane AP propagates longitudinally along the fibre and radially along the T-tubules, electrotonically (Adrian et al. 1969), or in a fast, homogeneous, regenerative $\mathrm{Na}^{+}$-dependent process (Huxley 1964; González-Serratos 1971; Bezanilla et al. 1972). T-tubules are invaginations of the plasma membrane that transversely extend into muscle fibres (they also have longitudinal components inside the fibre), and serve as a mean to rapidly carry electrical information from the surface to the interior of the muscle fibre, namely to the DHPR facing the SR membrane (Franzini-Armstrong and Porter 1964; Bezanilla et al. 1972; Edwards et al. 2012). The depolarization of the surface reaches the triadic region, where one T-tubule is surrounded by junctional SR segments from two different terminal cisternae (Porter and Palade 1957; Franzini-Armstrong and Porter 1964; Peachey 1965). In this region, arrays of molecules known as RyR and further identified as $\mathrm{Ca}^{2+}$ release channels face, vis à vis, but in alternate mode, the DHPR, located in the T-tubule membranes and arranged in groups of four, called tetrads (Block et al. 1988; Franzini-Armstrong and Jorgensen 1994; Franzini-Armstrong 1999). DHPR are heteropentamers formed by subunits $\alpha_{1}, \alpha_{2}$, $\beta, \gamma$, and $\delta$, whose function is regulated by membrane potential; the S4 transmembrane domains of $\alpha_{1}$ subunit constitute the voltage sensors. The electrical manifestation of the voltage sensor operation is a non-linear intramembrane charge movement, characterized by S-shaped voltage dependence (Schneider and Chandler 1973; Ríos and Pizarro 1991). The voltage change induces a still unclear conformational change in the DHPR that gates the opening of the RyR in a cooperative manner (see below) (Schneider and Chandler 1973; Ríos and Brum 1987; Ríos and Pizarro 1991; Ríos et al. 1993; Bezanilla 2000). DHPR function and expression is also regulated by the RyR and the JP-45/CSQ complex (Ávila and Dirksen 2000; Treves et al. 2009; Mosca et al. 2013).

RyR are high molecular weight ( $\sim 550 \mathrm{kDa}$ per monomer) homotetramers whose shape has been classically associated to that of a mushroom: a bulky cytoplasmic domain which has regulatory sites, and a transmembrane domain which allow the protein to function as a large conductance $\mathrm{Ca}^{2+}$ channel that regulates $\mathrm{Ca}^{2+}$ outflow from the SR to the cytoplasm (see below) (Smith et al. 1988; Lai et al. 1988; Takeshima et al. 1989; Wagenknecht et al. 1989; Franzini-Armstrong and Jorgensen 1994; Franzini-Armstrong 1999; Serysheva et al. 2007). Regions for intraluminal regulation have also been described (Goonasekera et al. 2007). The electron microscopy appearance of the RyR proteins is known as "feet". RyR 
activity and expression are regulated by adenosine triphosphate (ATP), $\mathrm{Mg}^{2+}, \mathrm{Ca}^{2+}$, redox status, phosphorylation/ dephosphorylation status, and several proteins including calsequestrin (CSQ), calmodulin, S100A1, FK 506 binding protein (FKBP), calumenin, triadin, junctin, and possibly by the SR protein-27 (SRP-27) and indirectly by SR protein 35 (SRP-35) (Lai et al. 1988; Meissner 1984; Coronado et al. 1994; Fill and Copello 2002; Wei et al. 2006; Jung et al. 2006; Goonasekera et al. 2007; Bleunven et al. 2008; Prosser et al. 2008; Treves et al. 2009, 2012; Wium et al. 2012).

In skeletal muscle, the RyR1 and the DHPR are in close apposition, constituting the $\mathrm{Ca}^{2+}$ release units (CRU), that are activated almost simultaneously as a response to an AP (Franzini-Armstrong and Jorgensen 1994; FranziniArmstrong 1999). Due to the alternate disposition of RyR and DHPR arrays, for each RyR under control of a tetrad, there is one molecule that is not (Franzini-Armstrong and Jorgensen 1994). In amphibian muscle fibres, the sizeable presence in the parajunctional region of another isoform of the RyR (Felder and Franzini-Armstrong 2002) the RyR3, increases the fractional number of RyR that are not under DHPR control. The alternate arrangements of RyR and DHPR, and the presence of extrajunctional RyR3, constitute the structural basis for the proposal of a dual mechanism of $\mathrm{Ca}^{2+}$ release (O'Brien et al. 1995; Ríos and Pizarro 1988). According to this, RyR facing DHPR are under control of the membrane potential while RyR that do not face DHPR are activated by $\mathrm{Ca}^{2+}$ through a positive feedback mechanism, initially studied in frog muscles, known as $\mathrm{Ca}^{2+}$-induced $\mathrm{Ca}^{2+}$ release (CICR) (Endo et al. 1970; Fabiato 1984; Endo 2009). Then, the RyR activation in the triadic region provokes an outflow of $\mathrm{Ca}^{2+}$ into the myoplasm (Smith et al. 1988; Escobar et al. 1994). The CICR mechanism, however, may not participate in the massive $\mathrm{Ca}^{2+}$ release in mammalian muscle, as it does in frog muscle (Figueroa et al. 2012), since the voltage-activated $\mathrm{Ca}^{2+}$ release mechanism is responsible for the rapid, and highly synchronized, $\mathrm{Ca}^{2+}$ release in mammalian muscles.

The rate of $\mathrm{Ca}^{2+}$ release from the SR may be over $200 \mu \mathrm{moles} / \mathrm{ms}$ in fast-twitch mammalian fibres and the cytoplasmic free $\mathrm{Ca}^{2+}$ concentration may increase up to $20 \mu \mathrm{M}$ (Baylor and Hollingworth 2003), from a resting concentration close to $100 \mathrm{nM}$ (Williams et al. 1990). Nonetheless, the peak values reported vary depending on the $\mathrm{Ca}^{2+}$ dye used, the calibration technique, the muscle type, whether it is amphibian or mammalian, and the muscle fibre type, slow or fast-twitch (Miledi et al. 1977; Klein et al. 1988; Konishi et al. 1991; Delbono and Stefani 1993; Shirokova et al. 1996; Baylor and Hollingworth 2003; Calderón et al. 2009, 2010, 2013). The amount of $\mathrm{Ca}^{2+}$ released during a single twitch in rat fasttwitch fibres seems to be constant over a range of $\mathrm{SR} \mathrm{Ca}^{2+}$ content and equals about $20 \%$ of the endogenous $\mathrm{Ca}^{2+}$ load (Posterino and Lamb 2003). For both slow- and fast-twitch fibres, total SR free $\mathrm{Ca}^{2+}$ content ranges from about 0.5 to $1 \mathrm{mM}$ and can hardly be depleted (Fryer and Stephenson 1996; Wang et al. 2012). The high amount of $\mathrm{Ca}^{2+}$ inside the SR is buffered by CSQ, whose conformation and affinity changes determines its ability to also regulate RyR and then modulate $\mathrm{Ca}^{2+}$ release (Wei et al. 2006; Royer et al. 2010). Once released, the $\mathrm{Ca}^{2+}$ spreads in a matter of milliseconds, and interacts with troponin C. $\mathrm{Ca}^{2+}$-troponin interaction eliminates the inhibition imposed by troponin I and tropomyosin on the actin-myosin interaction, allowing the thin filaments to slide over the thick ones, thus producing tension (Huxley 1969; Ebashi 1974; Baylor and Hollingworth 2003; Craig and Padrón 2004).

Cytoplasmic $\mathrm{Ca}^{2+}$ removal rate is approximately $50 \mu \mathrm{moles} / \mathrm{ms}$ and is initially buffered by soluble cytoplasmic proteins such as parvalbumin and is finally removed from the cytosol by the action of the SERCA, the mitochondria and the NCX, with fibre type-dependent kinetics (see "ECC and fibre types") (Hasselbach 1964; Heizmann et al. 1982; Gillis et al. 1982; Balnave and Allen 1998; Baylor and Hollingworth 2003). Cytosolic proteins transiently buffer $\mathrm{Ca}^{2+}$ with moderate kinetics, while the SERCA takes the $\mathrm{Ca}^{2+}$ back to the SR with slower kinetics. Parvalbumin is a $12 \mathrm{kDa}$ monomeric protein, that binds $\mathrm{Ca}^{2+}$ with high affinity and also binds $\mathrm{Mg}^{2+}$, playing a crucial role in fast muscles' relaxation (see below) (Heizmann et al. 1982; Füchtbauer et al. 1991). Mitochondria and NCX are also slow $\mathrm{Ca}^{2+}$ handling mechanisms. Recently, $\mathrm{Ca}^{2+}$ uptake by mitochondria has been directly visualized in living cells, using genetically encoded chemiluminescent and fluorescent $\mathrm{Ca}^{2+}$ sensors, specifically targeted to the mitochondrial matrix (see below) (Rizzuto et al. 1992; Rudolf et al. 2004; Rogers et al. 2007) and NCX has been shown to activate under different conditions (Balnave and Allen 1998; Calderón et al. unpublished results). Most of these mechanisms finally deliver $\mathrm{Ca}^{2+}$ to the SERCA. SERCA is a $110 \mathrm{kDa}$, type $\mathrm{P}$ pump, mainly located in the SR's longitudinal region; factors regulating its expression and function include $\mathrm{Ca}^{2+}, \mathrm{pH}$, thyroid hormones, and phospholamban and sarcolipin proteins (Odermatt et al. 1998; Hasselbach 1964, 1998; Hasselbach et al. 1975; Jorgensen and Jones 1986; James et al. 1989; Martonosi and Pikula 2003; Periasamy and Kalyanasundaram 2007). Three different genes encode 3 SERCA isoforms, but the number of isoforms produced by alternative splicing is higher (Martonosi and Pikula 2003; Periasamy and Kalyanasundaram 2007). This protein has 3 large cytoplasmic domains attached to a domain consisting of 10 hydrophobic trans-SR-membrane helices. Large movements, mainly of the cytoplasmic domains, mediate the $\mathrm{Ca}^{2+}$ pumping from the cytoplasm into the SR against its concentration gradient, reducing the cytoplasmic $\mathrm{Ca}^{2+}$ levels to nanomolar values in a matter of milliseconds, thus ensuring a fast relaxation of the skeletal muscles (Hasselbach 1964; MacLennan et al. 1985; Martonosi and Pikula 2003; Toyoshima and Mizutani 2004). 
Since some mechanisms $\left(\mathrm{Ca}^{2+}\right.$ pumps, NCX and $\mathrm{Ca}^{2+}$ leak) may take $\mathrm{Ca}^{2+}$ out of the cells, with a yet not well known kinetics in skeletal muscle, a mechanism to ensure store $\mathrm{Ca}^{2+}$ replenishment exists (see below) (Parekh and Penner 1997; Kurebayashi and Ogawa 2001; Pan et al. 2002; GonzalezNarvaez and Castillo 2007; Bolaños et al. 2009).

The previous description gives a brief overview of most of the knowledge gathered on ECC coupling in skeletal muscle over the past 60 years, using a combination of experimental approximations, some of which will be discussed below.

\section{Technical issues on the ECC study}

Cell preparations used in ECC study

\section{Enzymatic dissociation and hand dissection}

Intact muscle fibres for physiological experiments can be obtained by means of enzymatic dissociation and manual isolation. In the first technique, described by Bekoff and Betz (Bekoff and Betz 1977) and modified by others (Caputo et al. 2004; Calderón et al. 2009; Calderón 2013), different rat or mouse muscles (mainly flexor digitorum brevis (FDB), extensor digitorum longus -EDL-, soleus and interossei) are subjected to an enzymatic dissociation with collagenase to digest the connective tissue surrounding the fibres, and subsequently subjected to mechanical dissociation through the use of glasspipettes. The procedure yields complete, tendon-free muscle fibres. Once obtained, about $85 \%$ of the fibres contract immediately and remain excitable for up to 24-36 hours when kept in Tyrode solution or culture medium (Calderón et al. 2009, 2010; Calderón 2013). One limitation with the use of dissociated fibres is their susceptibility to movement artifacts when recording $\mathrm{Ca}^{2+}$ transients. This drawback, however, has been overcome with the use of N-benzyl-p-toluene sulphonamide (BTS), butanedione monoxime (BDM) (Sun et al. 2001) and laminin. BTS is a small molecule which inhibits myosin type II and avoids shortening of the fibres (Cheung et al. 2002; Shaw et al. 2003; Calderón et al. 2009, 2010). Laminin works as a substrate to which muscle fibres adhere, limiting their movement and allowing the recording of movement artifacts-free $\mathrm{Ca}^{2+}$ transients with the advantage of working for all fibre types (Calderón et al. 2009, 2010).

Manual isolation appeals to the researcher's ability to dissect a muscle to obtain bundles with usually a few tens of fibres, or to obtain an isolated fibre still attached to its tendons. The fibre's integrity can be visually verified by observing its response to an electrical stimulus (Caputo and Giménez 1967; Lännergren and Westerblad 1987; Baylor and Hollingworth 2003; Bruton et al. 2003).

Although it has been suggested that fibres may be damaged during the enzymatic dissociation procedure (Hollingworth et al. 2012), the morphological evaluation and measurements of the levels of resting basal $\mathrm{Ca}^{2+}$, electrical properties of the sarcolemma, charge movement, amplitude of the AP and release of $\mathrm{Ca}^{2+}$ from the SR (Bekoff and Betz 1977; Williams et al. 1990; Szentesi et al. 1997; Woods et al. 2004; Wang et al. 2007) have shown that enzymatic dissociation of different muscles renders functionally intact fibres. Moreover, recent results showed that these fibres reproduce results previously described in manually isolated ones, such as the fatigue-induced increase in intramitochondrial $\mathrm{Ca}^{2+}$ and the tetanic $\mathrm{Ca}^{2+}$ transient's amplitude reduction (Bruton et al. 2003; Calderón et al. 2011). Discrepancies between findings reported in different works (Calderón et al. 2010; Hollingworth et al. 2012) may have arisen from intrinsic differences between both preparations, such as the reduced sarcomere length found in dissociated fibres compared to manually isolated fibres mounted on transducers (Bolaños et al. 2008; Calderón et al. 2009).

\section{Mechanical and chemical fibre skinning techniques}

These techniques allow direct access to the interior of the muscle fibre, as both of them remove the sarcolemma, either mechanically (by microdissection) or with the use of glycerol or soft detergents such as Triton X-100 (Natori 1954; Wood et al. 1975; Lamb et al. 1995; Fryer et al. 1995; Knuth et al. 2006). The SR function can be preserved depending on the intensity of the treatment. It has been proven that in mechanically skinned fibres the T-tubules are resealed forming a closed compartment that allow the re-stablishment of ionic gradients and are capable of conducting AP. At the same time, the myoplasmic compartment remains open for experimental manipulation (Lamb et al. 1995; Fryer et al. 1995). One can hence determine, for instance, the effect of a change in $\mathrm{pH}$ or concentration of a metabolite like phosphate $(\mathrm{Pi})$ or lactate on the myofibrils sensitivity to $\mathrm{Ca}^{2+}$, and the maximum strength generated with a saturating amount of cytosolic $\mathrm{Ca}^{2+}$. As a disadvantage, these techniques may remove cytosolic compounds like gluthathione, ATP, and parvalbumin, which can make the reading of certain results somewhat difficult.

\section{Cut fibres preparation}

This preparation allows control of the fibre membrane potential by double or triple vaseline gap voltage clamp techniques and also gives access to the myoplasm (Hille and Campbell 1976; Kovács and Schneider 1978; Kovács et al. 1983). The fibres, usually from frog or rat, are manually dissected and then cut, keeping or not part of the tendons. After that, the fibres are mounted on a chamber that allows the control of the composition of the intracellular medium through the cut fibre ends while the central portion of the fibre is electrically isolated from the cut extremes, using vaseline strips. 


\section{Cell cultures}

Primary cultures and well-established myogenic cell lines, such as the mouse $\left(\mathrm{C}_{2} \mathrm{C}_{12}\right)$ and rat (L6), or the dyspedic 1B5 (Yaffe and Saxel 1977; Rando and Blau 1994; Moore et al. 1998), have ideal characteristics for the in vitro study of differentiation, development, and signalling, on a functional, biochemical, and molecular level. In both cases (primary cultures and cell lines), the cultures must be kept in a growth medium with up to $20 \%$ fetal bovine serum (FBS) until they reach $\sim 60-90 \%$ confluence to subsequently be induced to form myotubes, by reducing the amount of FBS in the culture medium or by its substitution for horse serum between 2 and $5 \%$. The functional results are limited to comparisons with early in vivo developmental stages, mainly because of the structural characteristics reached by myotubes formed in culture. When fibres isolated by enzymatic dissociation of FDB muscles from adult mice are kept in serum-free culture medium, they retain normal ECC properties for up to 7 days and are suitable for different physiological studies (Wang et al. 2007).

\section{Experimental procedures}

\section{Wide-field quantitative fluorescence and measurements of $\mathrm{Ca}^{2+}$ transients}

Over 45 years ago, Ridgway and Ashley (1967) were able to record global $\mathrm{Ca}^{2+}$ transients in electrically stimulated, intact muscle fibres. The authors injected the photoprotein aequorin, which emits light in presence of $\mathrm{Ca}^{2+}$. Due to the technique difficulty and stoichiometric problems, aequorin was substituted by metallochromic dyes, whose absorption spectra shift in the presence of $\mathrm{Ca}^{2+}$. However, these dyes were also substituted by the fluorescent ones due to the unsurpassed experimental advantages of the latter.

Usually, $\mathrm{Ca}^{2+}$ transients records obtained using fluorescent molecules have the following kinetic characteristics: (1) a rising phase, which reflects the $\mathrm{Ca}^{2+}$ outflow from the SR, and its free presence in the cytoplasm, (2) a peak, when $\mathrm{Ca}^{2+}$ outflow stops and $\mathrm{Ca}^{2+}$ removal mechanisms are already activated, and (3) a decay phase, which represents the sole operation of myoplasmic free $\mathrm{Ca}^{2+}$ removal mechanisms (Fig. 1). $\mathrm{Ca}^{2+}$ transients can be obtained in enzymatically dissociated or manually dissected fibres, in myotubes, and in cut fibres (Kovács et al. 1983; Westerblad and Allen 1991; Delbono and Stefani 1993; Caputo et al. 2004; Calderón et al. 2010). For these measurements, fluorescent indicators coupled to an acetoxymethyl (AM) ester moiety are commonly used, which allows them to diffuse into the cell. Once in the cytoplasm, endogenous esterases release the indicator molecule, which is now ready to bind $\mathrm{Ca}^{2+}$ and emit light (Tsien 1981). Fluorescent indicators in its salt form can also be injected into the cells, giving the possibility of determining the intracellular dye concentration and other dye- related data in a reliably way (Baylor and Hollingworth 1988; Konishi et al. 1991; Westerblad and Allen 1992).

In general, fluorescent $\mathrm{Ca}^{2+}$ dyes can be classified as ratiometric or non-ratiometric (Grynkiewicz et al. 1985; Minta et al. 1989; Raju et al. 1989; Takahashi et al. 1999; Katerinopoulos and Foukaraki 2002; Kao et al. 2010; Bruton et al. 2012). Non-ratiometric dyes can be excited with visible light and, when bound to $\mathrm{Ca}^{2+}$, their fluorescence intensity increases without showing an important maximum excitation or emission wavelength shift. In this group, low and high affinity dyes can be found, having a dissociation constant in the micromolar or nanomolar range, respectively. The most commonly used dyes of this type are Mag-Fura-2 (first described as ratiometric, also giving the possibility of being used as non-ratiometric; Raju et al. 1989; Konishi et al. 1991; Baylor and Hollingworth 2003), Fluo-3 (Caputo et al. 1994), Fluo-4 (Prosser et al. 2010), Rhod-2 (Escobar et al. 1994; Caputo et al. 1999; Bruton et al. 2003) and Mag-Fluo-4 (Caputo et al. 2004; Calderón et al. 2009, 2010). The most suitable dyes to study ECC in skeletal muscle seem to be the low affinity $\mathrm{Ca}^{2+}$ dyes, Mag-Fura-2 and Mag-Fluo-4 (Fig. 1), since they are well known and can reliably track fast, large and brief $\mathrm{Ca}^{2+}$ transients such as those found in skeletal muscle (Hollingworth et al. 2009; Baylor and Hollingworth 2011; Calderón et al. 2010, 2013). Their disadvantages include the possible signal "contamination" with $\mathrm{Mg}^{2+}$-induced fluorescence, the need for taking measures to avoid the appearance of movement artifacts (see "Enzymatic dissociation and hand dissection") in the $\mathrm{Ca}^{2+}$ transients and a more complex calibration procedure.

Ratiometric dyes, on the other hand, may show both intensity and spectrum changes when bound to $\mathrm{Ca}^{2+}$. The main examples of this group are: Fura-2 (Baylor and Hollingworth 1988; Westerblad and Allen 1991), Indo-1 (Chin and Allen 1998) and Mag-Fura-5 (Delbono and Stefani 1993; Szentesi et al. 1997). Their main disadvantages include the need for ultraviolet excitation and a more complex instrumentation. Also, with the exception of Mag-Fura-5, they may saturate and seem not to reliably track $\mathrm{Ca}^{2+}$ kinetics in skeletal muscle. One of the most important advantages of this group of dyes is the possibility of recording $\mathrm{Ca}^{2+}$ transients free of movement artifacts (Kao et al. 2010; Bruton et al. 2012) and their suitability for measuring myoplasmic basal $\mathrm{Ca}^{2+}$. Other advantages include their minimum $\mathrm{Mg}^{2+}$ affinity and the possibility of calibration disregarding the dye concentration.

Although for tracking $\mathrm{Ca}^{2+}$ changes focused on particular subcellular structures, some $\mathrm{Ca}^{2+}$ dyes may be used (Rhod-2, Mag-Fluo-4; Fluo-5N, CalciumOrange-5N; Bruton et al. 2003; Brochet et al. 2005; Bolaños et al. 2008; Kao et al. 2010), the genetically-encoded $\mathrm{Ca}^{2+}$ sensors seem to be now a better choice (Palmer and Tsien 2006; Rudolf et al. 2004; Tang et al. 2011; Wang et al. 2012).

As illustrated in Fig. 1, the kinetics of the single $\mathrm{Ca}^{2+}$ transients largely depend on the kinetic properties of the dye 


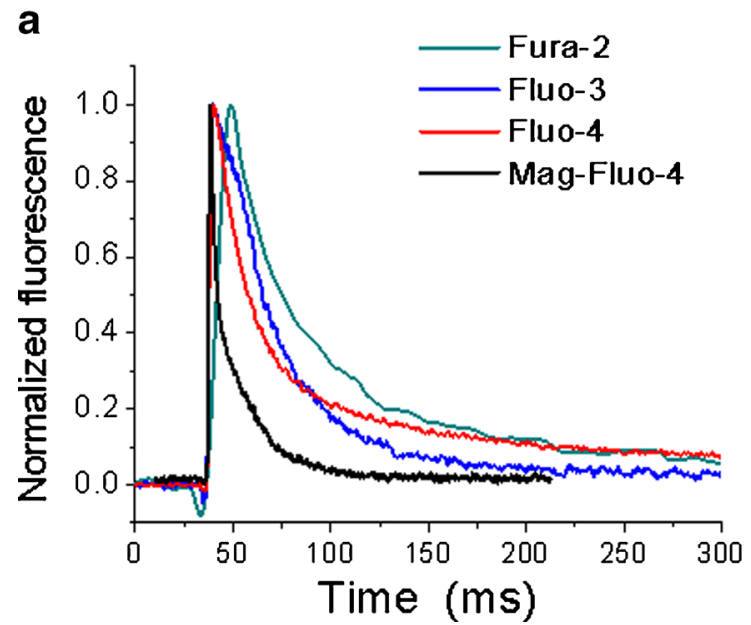

Fig. 1 Comparison of single $\mathrm{Ca}^{2+}$ transients' kinetics recorded in muscle fibres obtained by enzymatic dissociation of flexor digitorum brevis muscles from adult mice. Different cells were loaded with each of the $\mathrm{Ca}^{2+}$ dyes indicated in the figure and electrically stimulated. $\mathrm{Ca}^{2+}$ transients were recorded in an inverted fluorescence microscope using the appropriate set of filters, a photomultiplier and a Nikon amplifier. In (a),

used. In this figure, Mag-Fluo-4 is the only low-affinity $\mathrm{Ca}^{2+}$ dye and shows the best kinetics for tracking skeletal muscle $\mathrm{Ca}^{2+}$ transients. In any case, the researcher should know how to deal with the limitations of a given dye and also how to exploit its advantages, since the ideal $\mathrm{Ca}^{2+}$ indicator is still missing.

\section{Tension measurements}

For tension measurements, small bundles of fibres and manually isolated fibres are used (Caputo and Giménez 1967; Lännergren and Westerblad 1987; Baylor and Hollingworth 2003; Bruton et al. 2003; Edman 2005). Therefore, muscle fibres remain attached to their tendons. Isolated fibres or bundles are horizontally mounted on the experimental chamber and attached with small aluminum clips, on one end to a tension transducer and on the other to a hook attached to the chamber. Contractions are produced by suprathreshold stimulation through electrodes. Simultaneous measurements of $\mathrm{Ca}^{2+}$ and tension can be obtained (Westerblad and Allen 1991; Bruton et al. 2003; Baylor and Hollingworth 2003; Calderón et al. 2011). This allows to calculate, for instance, myofibrils' sensitivity to $\mathrm{Ca}^{2+}$ in intact fibres, or to follow the changes of both variables during muscle fatigue. Recently, a biological adhesive was successfully used to attach dissociated fibres to a tension transducer (Ward et al. 2011) ,opening up a large number of possibilities with this cellular preparation.

\section{Electrophysiology}

Membrane ionic current measurements, intramembrane charge movement recordings and studies of voltage dependence of $\mathrm{Ca}^{2+}$ release, through membrane voltage-clamp b

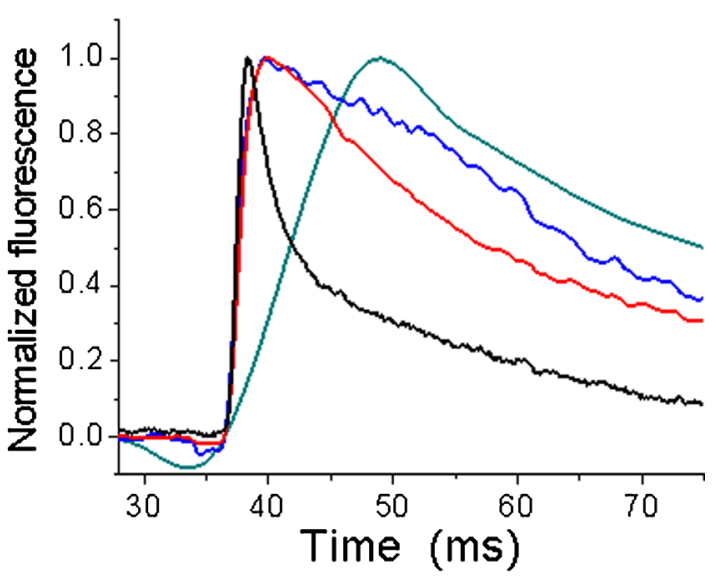

clear kinetic differences can be recognized, mostly derived from the different dissociation constants of the dyes used, being the fastest signal that obtained with Mag-Fluo-4 (black trace) and the slowest one that obtained with Fura-2 (green trace). In (b), the records are shown in an expanded time scale to better illustrate differences in the rising part of the signal

techniques are of great importance for the study of numerous aspects of physiology and physiopathology of skeletal muscle (Delbono and Stefani 1993; Szentesi et al. 1997; HernándezOchoa and Schneider 2012). Currently, the triple vaseline gap voltage clamp, the whole-cell patch-clamp and the siliconeclamp techniques are the most used for recording $\mathrm{Ca}^{2+}$ transients under controlled membrane potential conditions, in myotubes, intact or cut isolated fibres. In adult fibres, because of their length, it is convenient to use the vaseline-gap and silicone-clamp techniques to isolate areas of the fibres and thus restrict current measurements to small portions of the fibres. In the obtained records, the amplitude and voltage dependence are the most important variables to analyze. Depolarization occurs from a set voltage (holding potential) usually from -80 to $-100 \mathrm{mV}$, to a variable voltage. Depolarization records from -80 to $-10,0,+10$ and $+30 \mathrm{mV}$ are usually obtained (Delbono and Stefani 1993; Szentesi et al. 1997; Beam and Franzini-Armstrong 1997; Pouvreau et al. 2007a; Hernández-Ochoa and Schneider 2012).

In a different technique, by inserting purified proteins into artificial lipid bilayers and activating the passage of ions through them, it is possible to study their channel properties and to estimate their conductance, open probability, selectivity and drugs effects (Smith et al. 1988; Goonasekera et al. 2007).

\section{Confocal laser scanning microscopy and super-resolution microscopy}

Confocal laser scanning microscopy (CLSM), and, more recently, multiphoton microscopy, have allowed us to perform temporal and spatial precise analysis of ECC-related physiological phenomena at a subcellular level, besides the suitability 
of CLSM for structural studies (Cheng et al. 1993; Escobar et al. 1994; Rudolf et al. 2004; Brochet et al. 2005; Bolaños et al. 2008; Casas et al. 2010; Figueroa et al. 2012). Cells may be loaded with indicators such as di-8-ANEPPS and FM 1-43 to label sarcolemma and T-tubules and record transmembrane voltage; Rhod-2, Fluo-3 and Fluo-4 for cytoplasmic $\mathrm{Ca}^{2+}$; Endoplasmic Reticulum-Tracker Green (ERTG) for SR and MitoTracker Green, Rhod-2, CalciumOrange-5N, JC-1 and Tetramethyl rhodamine ethyl ester (TMRE) for different mitochondrial studies (Farkas et al. 1989; Escobar et al. 1994; Rudolf et al. 2004; Bolaños et al. 2008; Calderón et al. 2009; Casas et al. 2010; Manno et al. 2013). Fluorescent moleculescoupled antibodies and fluorescent proteins-coupled protein constructs are also visualized using CLSM. Confocal microscopy has the following advantages over optical microscopy and wide-field fluorescence: (1) higher z-resolution and better contrast, it allows us to obtain better structural (i.e. T tubules, SR or mitochondria) and functional information $\left(\mathrm{Ca}^{2+}\right.$ and transmembrane potential imaging), (2) allows us to obtain images for further analysis (temporary changes, fluorescence intensity measurements, and morphometric measurements, among others), (3) allows us to simultaneously register different structures or events for further joint analysis, and (4) allows us to perform optical sections, which is especially important to determine the location of fluorescent compounds, and to perform three-dimensional reconstructions, in addition to producing multidimensional images according to time ( $x t$ or $x y t$ modes). One limitation of CLSM has been its low temporal resolution when studying kinetics of $\mathrm{Ca}^{2+}$ transients with fast $\mathrm{Ca}^{2+}$ dyes. However, recently, some authors overcome this limitation, and were able to track $\mathrm{Ca}^{2+}$ transient's propagation with fast scanning confocal microscopy in rat fibres (Edwards et al. 2012).

Additionally, the use of CLSM combined with new techniques such as FRET (Förster resonance energy transfer) and SEER (Shifted excitation and emission ratioing) have allowed, among other findings, to study conformational coupling between DHPR and RyR and to obtain images which allow to quantify the $\mathrm{Ca}^{2+}$ inside the SR or dynamically image transmembrane voltage (Papadopoulus et al. 2004; Launikonis et al. 2005; Manno et al. 2013).

Although the theoretical background for super-resolution microscopy has been developed during the last two decades (Hell and Wichmann 1994; Klar et al. 2000; Gustafsson 2000; Schermelleh et al. 2010), this technique became commercially available very recently and only a few works have used it to study skeletal muscle ECC (Rausch et al. 2013), besides cardiac ECC (Jayasinghe et al. 2012; Scriven et al. 2013; Wong et al. 2013). The main advantage of the technique is providing a $x y$-resolution between 30 and $120 \mathrm{~nm}$, which recently allowed some authors to recognize a new pattern of RyR clustering in mouse FDB fibres (Rausch et al. 2013). The main disadvantages include the need for non-standard dyes in some devices, still limited temporal resolution and high costs.
Other procedures

(1) Electron microscopy (standard, metal-shadowed, cryomicroscopy and three-dimensional reconstructions) has generated important information on the triad structure, membrane systems (T-tubules and SR), DHPR-RyR interaction and SR-mitochondria relationship (Block et al. 1988; Serysheva et al. 2007; Boncompagni et al. 2009; also see below). Because there are no X-ray diffraction patterns of the whole DHPR and RyR proteins, due to the difficulties of crystallizing them, cryomicroscopy of isolated particles and three-dimensional reconstructions have been used for structural and functional characterization. However, the resolution obtained does not allow a clear non-ambiguous secondary structural assignment for some proteins (see below).

(2) Several molecular biology and genetic engineering techniques have provided valuable information on skeletal muscle in normal and pathological conditions, since they have allowed the functional evaluation of the expression (or absence) of proteins involved in ECC, i.e: (1) knockout mice for some proteins, including dysgenic mice lacking the subunit $\alpha-1$ of DHPR, and dyspedic mice, lacking RyR1 (Buck et al. 1997; Beam and FranziniArmstrong 1997; Prosser et al. 2008). Mice lacking CSQ or other minor ECC proteins have been under research during the past years (Paolini et al. 2007; Royer et al. 2010; Mosca et al. 2013); (2) gene silencing, as in the codifying gene for SR integral protein, JP-45, proving its importance for functional expression of DHPR (Anderson et al. 2006); and (3) production and extraction of recombinant proteins with high qualitative and quantitative performance in adult mammalian skeletal fibres, which has allowed researchers to evaluate the effect of mutated ion channel's expression and endogenous protein over-expression, such as DHPR, on ECC (DiFranco et al. 2006, 2011).

\section{Particular issues on ECC}

Dihydropyridine receptor-ryanodine receptor structure and coupling

There is evidence indicating a mechanical, bidirectional conformational coupling between DHPR and RyR in the skeletal muscle (Nakai et al. 1996; Ávila and Dirksen 2000; Fill and Copello 2002; Paolini et al. 2004), which would be mediated by regions of the internal loop joining DHPR's II and III transmembrane domains and a specific short RyR region (Tanabe et al. 1990; el-Hayek et al. 1995; Leong and MacLennan 1998; Casarotto et al. 2006), although several studies suggest that there are multiple RyR1 regions interacting with DHPR 
(Protasi et al. 2002) and multiple DHPR subunits doing so with the RyR1 (Papadopoulus et al. 2004).

Two important and related developments opened the way for clarifying, at a molecular level, the roles of DHPR and RyR, and their relationship in ECC: (1) the cloning and sequencing of the complementary DNA (cDNA) that encoded for the $\alpha 1$ subunit of DHPR (Tanabe et al. 1987), and of the skeletal muscle RyR (Takeshima et al. 1989) and (2) the availability of mice with genetic alterations at level of the DHPR, or at level of the RyR. In the case of DHPR, it was shown that mice with a mutation in the $\alpha 1$ subunit of this molecule, dysgenic mice, lacked the L-type $\mathrm{Ca}^{2+}$ current and presented greatly reduced intramembrane charge movement (Beam et al. 1986). These results provided the first hint that DHPR could have a dual function, serving both as voltage-activated $\mathrm{Ca}^{2+}$ channels and as voltage sensors for ECC, an idea reinforced by the simultaneous evidence provided by Ríos and Brum (1987) that the DHPR were the molecules generating the intramembrane charge movement, which represents the electrical manifestation of the voltage sensors operation. Definitive evidence in favour of this idea was obtained by the fact that expressing skeletal muscle DHPR $\alpha 1$ subunit in dysgenic myotubes restored both the slow $\mathrm{Ca}^{2+}$ current (Tanabe et al. 1988) and the intramembrane charge movement (Adams et al. 1990).

An elegant experimental strategy was developed to determine the regions of the DHPR important for ECC, based on the differential sensibility of skeletal and cardiac ECC to extracellular $\mathrm{Ca}^{2+}$ and the use of myotubes of dysgenic animals that did not express DHPR (Tanabe et al. 1990). Injection of cDNA codifying for the cardiac isoform of the DHPR reproduced the cardiac type of ECC, that required the presence of external $\mathrm{Ca}^{2+}$ for contracting in response to electrical stimulation and was disrupted by $\mathrm{Cd}^{2+}$ poisoning. Injection of cDNA, codifying for skeletal type DHPR, reproduced the skeletal ECC with injected myotubes contracting in the absence of external $\mathrm{Ca}^{2+}$ and not sensitive to $\mathrm{Cd}^{2+}$. Further experiments using expression plasmids, in which only the loops between I-II and II-III domains of the DHPR were of skeletal origin, showed that the skeletal region between repeats II and III was a sufficient determinant for skeletal type ECC.

Most DHPR-RyR interaction studies have been based on site-directed mutagenesis of amino acids located in specific domains. However, the movements of different domains involved in such interactions are not completely clear, due to lack of information from crystallography or magnetic resonance studies of both channels under different circumstances. Although the three-dimensional structure of the isolated DHPR II-III loop is already known (Casarotto et al. 2006), it is still uncertain if it assumes a different structure when binding with RyR or if it remains unchanged in relation to the complete DHPR structure. The $\beta_{1 \text { a }}$ subunit of the DHPR has also been shown to be important for ECC coupling, and ongoing work is devoted to clarify its role in interacting with and modulating RyR, as well as its role in the adecuate targeting (i.e. forming tetrads) of DHPR to the T-tubules (Pérez et al. 2013; Rebbeck et al. 2013).

So far, most structural information on DHPR and RyR structures comes basically from cryomicroscopy studies and three-dimensional reconstructions (Wagenknecht et al. 1989; Ludtke et al. 2005; Samsó et al. 2005, 2009; Serysheva et al. 2007). Despite the fact that several teams are solving the structure of both proteins, only recently have sub-nanometric resolution images been published $(9.6 \AA$ for the whole RyR (Ludtke et al. 2005) and $2.5 \AA$ for the structure generated by the 559 aminoacids of the N-terminal region of the RyR (Tung et al. 2010). The authors have specially focused on the RyR's pore structure at its closed state. Ludtke et al. (2005) identified $5 \alpha$ helices per monomer in the transmembrane region and suggested that helices 1 of each subunit form the pore, and helices 2 , the selectivity filter. Samsó et al. (2005) suggested the existence of at least 6 transmembrane helices per monomer, and described in some detail the structures known as columns (inner branches), which connect the transmembrane portion with the great cytosolic domain. It is possible that the pore's structure is similar to some already published $\mathrm{K}^{+}$channel structures (Doyle et al. 1998; Jiang et al. 2002; Ludtke et al. 2005; Samsó et al. 2005, 2009). Recently, an image of the open channel (at $10.2 \AA$ ) was obtained and moderate conformational changes were recognized when compared to the closed state. The cytoplasmic domains move outward and the three constrictions identified by the authors in the ion pathway show a wider central passage (Samsó et al. 2009).

The highest resolution obtained $(9,6 \AA$ in RyR 1 and $30 \AA$ in DHPR) is not clear enough to show details such as: (1) the exact molecular mechanism involved in receptor's interactions, (2) presence, distribution and movement of $\alpha$ helices and $\beta$ sheets to explain, for instance, how the signal is transmitted from the DHRP to the RyR and how the information from the RyR regulators is transmitted from somewhere in the protein to the pore, to allow $\mathrm{SR} \mathrm{Ca}^{2+}$ release, (3) delimitation of the different subunits in each protein, and (4) the number of RyR helices going through the SR membrane, since the proposed number of transmembrane helices varies between 4 and 10-12 per monomer (Takeshima et al. 1989; Zorzato et al. 1990; Samsó et al. 2009).

The 2.5-Å resolved structure of the N-terminal domains of the RyR shows that it is located in the cytoplasmic portion of the protein, and the domains orientation likely represents the closed state of the channel (Tung et al. 2010). In this region, the positions of multiple disease-mutations and some regions of intersubunit interactions can be mapped, but it is likely that, in spite of the high resolution, no clear information on the above questions will be obtained by this structure. The answer to these and other issues relies on obtaining a complete structural image of both DHPR and RyR channels with at least a 36-Å resolution. 
Isolated protein images do not necessarily reflect the structure of complexes such as the triad. Images of isolated rabbit triads (Wagenknecht et al. 2002) with an approximate resolution of $6 \mathrm{~nm}$, obtained through several techniques, confirmed findings previously made by other authors (FranziniArmstrong and Porter 1964; Block et al. 1988; FranziniArmstrong and Jorgensen 1994; Franzini-Armstrong 1999) and drew attention to the existence of some new structural characteristics: (1) there could possibly be a 5-nm-wide structure under the SR's internal membrane, whose nature is still unknown, (2) CSQ particles seem to be interconnected within the SR, (3) inside the T-tubule's lumen, there appear to be structures whose molecular nature is still unknown but could play a structural role, and (4) the presence of structures covering the distance from the RyR's cytoplasmic region all the way to the T-tubule was found, which cannot be categorized in a clear protein domain, but could be DHPR loops. In spite of the advantages of this technique, the results obtained could be affected by artifacts during the sample processing, and by the low resolution of the images.

Aside from the above, we still need to know the threedimensional structure of triadic major and minor proteins, including previously identified and some still unidentified ones. Although some models of the triadic complex have been recently put forward and the specific domains and aminoacids involved in intra- and interprotein interactions are being identified (Wagenknecht et al. 2002; Treves et al. 2009; FourestLieuvin et al. 2012; Boncompagni et al. 2013), the huge amount of proteins and expected interactions among them that regulate ECC, and which may also function as molecular determinants of the shape of the membranous components of the triad, makes the work on these issues still far from finished. Nowadays, despite almost three decades of research on the DHPR-RyR coupling issue, two basic questions remain unanswered: how are different signals transmitted from the bulk of the channel to the pore, and how is the ion gating mechanism of RyR?

\section{ECC and fibre types}

In 1873, Ranvier stated that there were pale and red muscles, being different mainly regarding their contraction speed (Ranvier 1873). Decades later, a more complete profile of both types of fibres was generated and new fibre types were described (Dubowitz and Pearse 1960; Brooke and Kaiser 1970; Bär and Pette 1988; Schiaffino et al. 1989). Since four fibre types based on myosin heavy chain (MHC) presence have been described, I, IIA, IIX/D and IIB (there are also hybrid fibres), one important question that raises is whether ECC proteins and $\mathrm{Ca}^{2+}$ transient kinetics differ among all fibre types.

The molecular machinery involved in ECC is qualitatively (different isoforms) and quantitatively (different amount of proteins or different kinetics) different between slow and fast-twitch fibres (Table 1). The information presented in this table discriminates between slow- and fast-twitch fibre types, since the information is not available for each MHC-based fibre type. A great variability regarding the proteins involved in both $\mathrm{Ca}^{2+}$ release and $\mathrm{Ca}^{2+}$ removal from the myoplasm is evident. The most striking difference is found in parvalbumin concentration, ranging from almost zero in the slowest fibres up to $1 \mathrm{mM}$ in the fastest fibres.

The differences mentioned in Table 1 constitute the biochemical and structural bases for the $\mathrm{Ca}^{2+}$ transients variability found among fibre types (Eusebi et al. 1980; Carroll et al. 1997; Bottinelli and Reggiani 2000; Baylor and Hollingworth 2003; Reggiani and te Kronnie 2006; Calderón et al. 2009, 2010).

Single $\mathrm{Ca}^{2+}$ transients obtained using Mag-Fluo-4 can be classified according to their kinetics into two different morphologies (Calderón et al. 2009, 2010). One morphology, found in fibres type I and IIA, is slower, wider and of less amplitude and was called morphology type I (MT-I). The other morphology, found in fibre types IIX/D and IIB, is faster, narrower and of higher amplitude and was called morphology type II (MT-II). An example of the $\mathrm{Ca}^{2+}$ transients found in different fibre types from mice muscles is illustrated in Fig. 2. Since only minor differences can be recognized between fibres type I and IIA, for the sake of clarity, we have pooled in Table 2 the kinetics of a large number of MT-I fibres obtained from soleus muscles. The data are compared with the pooled values obtained in EDL fibres, since all of them are MT-II. Significant differences can be recognized in all parameters describing amplitude, rising and decay kinetics between soleus and EDL signals.

Tetanic $\mathrm{Ca}^{2+}$ transients of the fibres type I and IIA show a staircase morphology (MT-I). In these transients, the decay can be fitted by a single exponential function. On the other hand, fibres type IIX/D and IIB have tetanic $\mathrm{Ca}^{2+}$ transients whose decay is better fitted with a biexponential function (MT-II) (Calderón et al. 2009, 2010).

In general, regarding $\mathrm{Ca}^{2+}$ transients and fibre types, it can be concluded that transient's kinetics show a continuum from the slowest kinetics, obtained in the type I fibres, to the fastest ones, obtained in types IIX and IIB. Remarkably, type IIA fibres are fast regarding $\mathrm{Ca}^{2+}$ release and slow regarding $\mathrm{Ca}^{2+}$ clearance (Calderón et al. 2009, 2010). The differences in kinetics of the $\mathrm{Ca}^{2+}$ twitch and tetanic transients seem to underlie the different kinetics of contractile characteristics of slow and fast muscles (Calderón et al. 2010).

One application of the easily recognizable difference found between MT-I and MT-II records is the possibility of functionally recognizing fibre types while still alive during physiological experiments in which $\mathrm{Ca}^{2+}$ transients are recorded (Calderón et al. 2011, unpublished results).

Ongoing work has addressed the mechanisms responsible for the $\mathrm{Ca}^{2+}$ transient's kinetics differences. The biochemical differences shown in Table 1 and new results suggest that 
Table 1 Biochemical and structural differences in ECC between slow and fast-twitch mammalian fibre types

\begin{tabular}{|c|c|c|c|c|c|}
\hline \multirow[t]{2}{*}{ Proteins } & \multicolumn{2}{|l|}{ Slow-twitch fibres } & \multicolumn{2}{|l|}{ Fast-twitch fibres } & \multirow[t]{2}{*}{ References } \\
\hline & Isoform & $\begin{array}{l}\text { Content/ } \\
\text { kinetics }\end{array}$ & Isoform & $\begin{array}{l}\text { Content/ } \\
\text { kinetics }\end{array}$ & \\
\hline DHPR & $\alpha-1 S$ & + & $\alpha-1 S$ & +++ & $\begin{array}{l}\text { Hollingworth and Marshall 1981; Lamb and Walsh 1987; } \\
\text { Franzini-Armstrong et al. 1988. }\end{array}$ \\
\hline RyR & RyR1 & + & RyR1 & +++ & $\begin{array}{l}\text { Franzini-Armstrong et al. 1988; Appelt et al. 1989; Damiani } \\
\text { and Margreth } 1994 .\end{array}$ \\
\hline PV & $\alpha-\mathrm{PV}$ & - to + & $\alpha-\mathrm{PV}$ & ++ to ++++ & $\begin{array}{l}\text { Heizmann et al. 1982; Leberer and Pette 1986; Schmitt and } \\
\text { Pette 1991; Füchtbauer et al. } 1991 .\end{array}$ \\
\hline SERCA & SERCA2a & + & SERCA1a & + to ++ & $\begin{array}{l}\text { Leberer and Pette 1986; Dulhunty et al. 1987; Ferguson } \\
\text { and Franzini-Armstrong 1988; Periamasy and } \\
\text { Kalyanasundaram } 2007 .\end{array}$ \\
\hline Phospholamban & Phospholamban & + & Phospholamban & - & Jorgensen and Jones 1986. \\
\hline Sarcolipin & Sarcolipin & + & Sarcolipin & +++ & Odermatt et al. 1998. \\
\hline Calsequestrin & $\begin{array}{l}\mathrm{CSQ}^{*} \text { fast and } \\
\mathrm{CSQ}_{\text {cardiac }}\end{array}$ & + & $\mathrm{CSQ}_{\text {fast }}$ & + & Leberer and Pette 1986; Damiani and Margreth 1994. \\
\hline SRP-27 & SRP-27 & + & SRP-27 & +++ & Bleunven et al. 2008 \\
\hline $\mathrm{NCX}$ & NCX1 & ++ & NCX1 and 3 & + & Fraysse et al. 2001; Hudecova et al. 2004 \\
\hline TnC, TnI, TnT & $\begin{array}{l}\text { TnC slow } \\
\text { TnI slow } \\
\text { TnT slow }\end{array}$ & + & $\begin{array}{l}\text { TnC fast } \\
\text { TnI fast } \\
\text { TnT fast }\end{array}$ & ++ & Bottinelli and Reggiani 2000. \\
\hline mATPase & Type I & + & $\begin{array}{l}\text { Types IIA, IIX/D } \\
\text { and IIB }\end{array}$ & ++ to +++ & $\begin{array}{l}\text { Dubowitz and Pearse 1960; Brooke and Kaiser 1970; Bär } \\
\text { and Pette 1988; Schiaffino et al. 1989; Bottinelli } \\
\text { and Reggiani 2000. }\end{array}$ \\
\hline
\end{tabular}

$D H P R$ dihydropyridine receptors; $R y R$ ryanodine receptors; $P V$ parvalbumin; $S E R C A$ sarcoendoplasmic reticulum $\mathrm{Ca}^{2+} \mathrm{ATPase}^{2} C S Q$ calsequestrin; $S R P-27$ sarcoplasmic reticulum protein-27 kDa; $N C X \mathrm{Na}^{+} / \mathrm{Ca}^{2+}$ exchanger; $T n C$ troponin C; TnI troponin I; TnT troponin T; $m A T P a s e$ myofibrillar Aband adenosine triphosphatase

- indicates absence of the protein; ++ indicates approximately twofold; +++ between twofold and tenfold; ++++ more than tenfold, in all cases compared to a reference of +

higher DHPR and RyR content explain differences in the rising phase of the $\mathrm{Ca}^{2+}$ transients and that PV content and SERCA kinetics explain most of the decay differences (Calderón et al.
2009, 2010, unpublished results). Other mechanisms such as mitochondria and NCX only play a minor role in explaining the differences (Calderón et al., unpublished results).

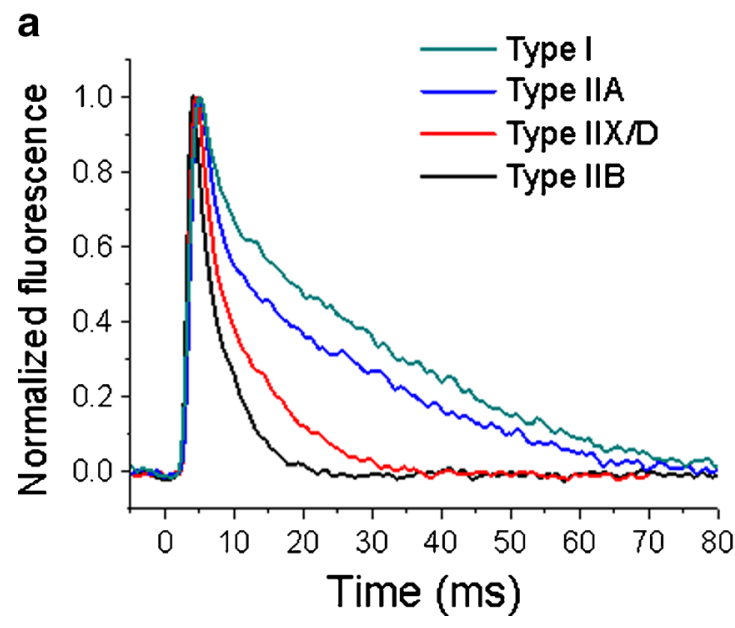

Fig. 2 Time course of single $\mathrm{Ca}^{2+}$ transients of different fibre types obtained by enzymatic dissociation of extensor digitorum longus and soleus muscles from adult mice and typed by polyacrylamide gel b

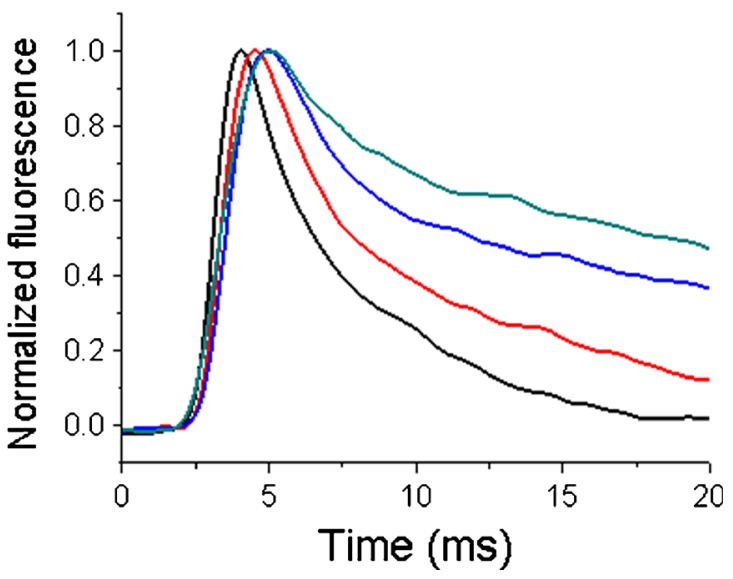

electrophoresis. The cells were loaded with Mag-Fluo-4. A pattern can be recognized, with the pair I and IIA being the slowest and the pair IIX/D and IIB being the fastest both during decay (a) and rise (b) 
Table 2 Kinetic parameters of soleus and EDL single $\mathrm{Ca}^{2+}$ transients from adult mice

\begin{tabular}{|c|c|c|c|c|c|c|c|c|c|c|}
\hline \multirow[t]{2}{*}{ Muscle } & \multirow[t]{2}{*}{$n$} & \multirow[t]{2}{*}{$\Delta \mathrm{F} / \mathrm{F}$} & \multirow{2}{*}{$\begin{array}{l}10-90 \% \text { Rise } \\
\text { time (ms) }\end{array}$} & \multirow{2}{*}{$\begin{array}{l}\text { Half-width } \\
(\mathrm{ms})\end{array}$} & \multirow{2}{*}{$\begin{array}{l}\text { Decay time } \\
(\mathrm{ms})\end{array}$} & \multicolumn{2}{|c|}{ Time constants (ms) } & \multirow[t]{2}{*}{$\mathrm{A}_{1}(\%)$} & \multirow[t]{2}{*}{$\mathrm{A}_{2}(\%)$} & \multirow[t]{2}{*}{$\Delta \mathrm{F} / \mathrm{RT}$} \\
\hline & & & & & & $t_{1}$ & $\mathrm{t}_{2}$ & & & \\
\hline Soleus* & 45 & $0.51 \pm 0.03$ & $1.56 \pm 0.04$ & $15.73 \pm 0.95$ & $61.35 \pm 2.41$ & $3.14 \pm 0.11$ & $43.63 \pm 2.23$ & $27.17 \pm 1.32$ & $72.83 \pm 1.32$ & $0.34 \pm 002$ \\
\hline EDL & 26 & $0.65 \pm 0.02$ & $1.08 \pm 0.03$ & $4.07 \pm 0.2$ & $15.92 \pm 0.88$ & $1.58 \pm 0.07$ & $9.99 \pm 0.67$ & $39.45 \pm 1.47$ & $60.55 \pm 1.47$ & $0.61 \pm 0.03$ \\
\hline
\end{tabular}

Values are mean \pm SEM

$E D L$ Extensor digitorum longus; $A 1$ amplitude of fast component of decay; $A 2$ amplitude of slow component of decay, $\Delta F / R T$ ratio of amplitude to rise time ${ }^{*} p<0.05$ for all comparisons between each one of the parameters (i.e. $\Delta \mathrm{F} / \mathrm{F}$ of soleus vs. EDL, $10-90 \%$ rise time of soleus vs. EDL, etc.). From: Calderón 2013, with permission

\section{ECC and muscle fatigue}

The transient and progressive decrease in skeletal muscle performance during continuous stimulation is known as fatigue (Fitts 1994; Allen et al. 2008). This is a complex phenomenon with central and peripheral components (BiglandRitchie and Woods 1984; Abbiss and Laursen 2005; Allen et al. 2008). Central fatigue involves events occurring prior to the ECC phenomenon, while peripheral fatigue involves events including ECC and other phenomena occurring inside the muscle fibre as a consequence of its activation.

Although different models to study muscle fatigue show different complexity, it seems that data gathered with a relatively simple model such as the one of isolated fibres can be used to understand some fatigue mechanisms in more complex models (Place et al. 2010). The most important addressed questions on fatigue are: (1) what is the cause of skeletal muscle fatigue, and (2) what is the mechanism by which muscle fatigue develops?

In several preparations, fatigue has been shown to be mainly peripheral (Grabowski et al. 1972; Bigland-Ritchie and Woods 1984; Moussavi et al. 1989; Kent-Braun 1999; Place et al. 2008, 2010), explained in part by alterations in the $\mathrm{Ca}^{2+}$ release mechanism (Grabowski et al. 1972; Allen et al. 1989; Westerblad and Allen 1991). In the same way, alterations of the SERCA function and slowing of single-twitch and tetanic relaxation have been demonstrated as a result of fatigue (Gollnick et al. 1991; Westerblad and Lännergren 1991; Westerblad and Allen 1993; Green 1998; Leppik et al. 2004), but the slowing of relaxation cannot be totally explained by the decreased SERCA pumping rate (Westerblad andAllen 1993). Other phenomena, such as a decrease in the intra-SR $\mathrm{Ca}^{2+}$ content and the damage of membrane systems involved in ECC, may also be implicated (Takehura et al. 2001; Tupling 2004). An alteration of the inactivation of the $\mathrm{Ca}^{2+}$ release mechanism seems not to mediate $\mathrm{Ca}^{2+}$ release disturbances found in fatigue (Calderón et al. 2011).

Although a wealth of evidence supports the concepts according to which both a decrease in AP amplitude or ATP depletion can be ruled out as causes of fatigue (Luttgau 1965;
Grabowski et al. 1972; Nassar-Gentina et al. 1978; Moussavi et al. 1989; Allen et al. 2002), recent findings, suggesting that localized ATP decrease close to critical cellular regions may be important for fatigue (Allen et al. 1997) or that an AP decrease in fatigued fibres can be measured by SEER (Manno et al. 2013), warrant further research on these topics.

ECC alterations during fatigue are strongly supported by the fact that, in a fatigued muscle, tension development can be reactivated by caffeine (Grabowski et al. 1972; Allen et al. 1989) and because it was actually proved that fatigued fibres have reduced tetanic $\mathrm{Ca}^{2+}$ transients (Westerblad and Allen 1991; Calderón et al. 2011). The ECC alteration, however, is more notorious in fast-twitch fibres compared to slow ones (Calderón et al. 2011), as expected by the known profile of fatigability of the different fibre types (Burke et al. 1973; Petrofsky and Lind 1979; Westerblad and Allen 1991; Bruton et al. 2003).

Metabolic factors, such as changes in $\mathrm{Ca}^{2+}$ itself, ATP, phosphocreatine $(\mathrm{PCr}), \mathrm{H}^{+}, \mathrm{Mg}^{2+}$, $\mathrm{Pi}$ and reactive oxygen species (ROS) concentrations observed during fatigue may be involved in altering the ability of the SR to release and reuptake $\mathrm{Ca}^{2+}$ (Lamb 2002; Tupling 2004; Allen et al. 2008; Calderón-Vélez and Figueroa-Gordon 2009).

Lactate accumulation and acidosis were the most claimed factors in explaining the decrease in muscle performance; however, its role has been challenged, although not without some controversy (Hill and Kupalov 1929; Westerblad 1999; Westerblad et al. 2002; Pedersen et al. 2004; Bangsbo and Juel 2006), even when $\mathrm{pH}$ values as low as 6.5 and lactate increase have been documented in several works as related to fatigue (McCully et al. 1991; Lindinger and Heigenhauser 1991; Kent-Braun et al. 1993; Kent-Braun 1999). pH reduction seems to decrease fibre's maximum strength, myofibrillar $\mathrm{Ca}^{2+}$ sensitivity and SR ability to release $\mathrm{Ca}^{2+}$ (Rousseau and Pinkos 1990; Fitts 1994; Lamb 2002; Knuth et al. 2006).

Another possible mechanism involving ECC as a potential fatigue site could be that the increase in basal myoplasmic $\mathrm{Ca}^{2+}$ $\left(\mathrm{Ca}^{2+}{ }_{\text {myo }}\right)$ found during the development of fatigue (Westerblad and Allen 1991; Caputo et al. 1994) may disrupt DHPR-RyR interaction (Lamb 2002). This seems to be associated to an 
alteration of the fibre to produce tension although the SR's ability to deal with $\mathrm{Ca}^{2+}$ does not become altered (Lamb et al. 1995; Verburg et al. 2005). SERCA function alteration (Green 1998; Westerblad and Lännergren 1991; Westerblad and Allen 1993; Leppik et al. 2004; Tupling 2004) could explain the persisting increase of $\mathrm{Ca}^{2+}{ }_{\text {myo }}$ leading to the $\mathrm{ECC}$ disruption and subsequently to a decrease in $\mathrm{Ca}^{2+}$ release after each stimulus. Opposite to this, it was suggested that a more important factor for the production of uncoupling is the localized increase of $\mathrm{Ca}^{2+}$ near the triad, associated to each tetanus, instead of the increase of basal $\mathrm{Ca}^{2+}{ }_{\text {myo }}$ (Verburg et al. 2006).

Although free myoplasmic $\mathrm{Mg}^{2+}$ increases during repeated stimulation (Westerblad and Allen 1992) and it is an inhibitor of the $\mathrm{SR} \mathrm{Ca}^{2+}$ release (Meissner 1984), $\mathrm{Mg}^{2+}$ does not have an important fatiguing effect unless reaching very high concentrations, which do not occur in a fatigued muscle fibre (Westerblad and Allen 1992; Lamb and Stephenson 1994).

Even though theoretical considerations could also support a role for ROS and free radicals in fatigue (Barclay and Hansel 1991; Sen 1995; Reid 2001; Darnley et al. 2001), by altering $\mathrm{Ca}^{2+}$ release from the SR (Brotto and Nosek 1996; Oba et al. 2002; Hidalgo 2005; Bruton et al. 2008), or by reducing myofibril's sensitivity to $\mathrm{Ca}^{2+}$ in mammalians (Moopanar and Allen 2005, 2006; Bruton et al. 2008; Reardon and Allen 2009), conflicting results are available on whether these species are actually produced during a repetitive stimulation protocol in different experimental preparations (Davies et al. 1982; Reid et al. 1992; Kanter et al. 1993; Bruton et al. 2008; van der Poel et al. 2008) and thus on whether their effect would be physiologically relevant to explain fatigue-induced ECC alterations in mammalians. The issue of the relationship among high temperature-ROS and fatigue seems to be illustrative. High temperature may increase ROS production in rodents, and ROS may induce fatigue (van der Poel et al. 2008; Reardon and Allen 2009; Michaelson et al. 2010; see also Place et al. 2009); however, high temperature did not alter fatigability in some reports (Place et al. 2009; Reardon and Allen 2009).

Nowadays, we are not certain about what are the exact physiological targets of free radicals and ROS in fatigue, what is the main source of ROS during repetitive contraction (see van der Poel et al. 2008; Michaelson et al. 2010), or if the lipid peroxidation may explain the alterations of the different ECCrelated proteins affected in the fatigue state and which are the chemical species involved. Until now, the results depend on the animal species, the techniques used for detecting ROS and the experimental protocols applied (muscle preparation, stimulation duration and temperature). Some recently developed tools may help solve technical problems with the detection of intracellular ROS and their role in muscle fatigue (Pal et al. 2013).

During the last two decades, an increase in free myoplasmic Pi has emerged as an important cause of fatigue. Pi meets important requirements to be considered as cause of ECC fatigue. Firstly, its change has a time course similar to the time course of the fatigue-induced $\mathrm{Ca}^{2+}$ kinetic changes (Westerblad and Allen 1991; Calderón et al. 2011). Changes in Pi can start early during the fatigue development, although are more notorious during the second half of the stimulation periods (Bergström and Hultman 1988; Moussavi et al. 1989; Kent-Braun et al. 1993; Kent-Braun 1999); several studies have shown that $\mathrm{Pi}$ is important for the early changes in the kinetics of $\mathrm{Ca}^{2+}$ signals (Dahlstedt et al. 2001; Westerblad et al. 2002). Secondly, an increase in Pi can explain the most important fatigue-induced $\mathrm{Ca}^{2+}$ kinetic changes (Westerblad and Allen 1991; Calderón et al. 2011). Pi can regulate both the release of $\mathrm{Ca}^{2+}$ and the function of SERCA (Duke and Steele 2000; Dahlstedt et al. 2001; Westerblad et al. 2002) and it seems to favor $\mathrm{Ca}^{2+}$ deposit inside the SR, in the form of $\mathrm{Ca}^{2+}$ phosphate, which diminishes the amount of $\mathrm{Ca}^{2+}$ available for release (Fryer et al. 1995; Dutka et al. 2005). It can also decrease myofibrillar $\mathrm{Ca}^{2+}$ sensitivity (Fitts 1994; Westerblad et al. 2002). Thirdly, the differential change in Pi observed in slow and fast fibres during contraction gives support to the differential alteration seen in the rising and decay phase of tetanic $\mathrm{Ca}^{2+}$ transients demonstrated in different fibre types during fatigue (He et al. 2000; see Calderón et al. 2011). And, fourthly, Pi concentration manipulation modifies in the same way the fatiguing properties of different muscles (Dahlstedt et al. 2001; Westerblad et al. 2002).

The development and availability of Pi fluorescent indicators would be of great impact to prove a direct relationship between intracellular changes of the metabolite and the phenomena known to occur during fatigue. Also, to confirm the role of Pi on muscle fatigue, the management of and the sensitivity to $\mathrm{Pi}$ alterations by the different fibre types in different experimental models should be evaluated.

Other questions are still open, such as: (1) what are the kinetics and mechanisms of muscle fatigue in developing or ageing fibres, (2) which mechanisms explain the fatigueresistant properties found in slow vs. fast-twitch fibres, and (3) what is the role of ECC regulators or minor proteins in muscle fatigue (see Prosser et al. 2010)?

\section{Contractile potentiators}

The early observation by Kahn and Sandow (1950) that nitrate augmented the twitch response of frog skeletal muscle led to the demonstration by Hodgkin and Horowicz (1960) that nitrate and other anions, of the lyotropic series $\mathrm{SCN}>\mathrm{I}>$ $\mathrm{NO}_{3}>\mathrm{Br}>\mathrm{Cl}$, shifted, in this order of potency, the relationship between contractile force and membrane potential, toward more negative potentials, thus reducing the contractile threshold, that in frog fibres is around $-50 \mathrm{mV}$ (Sandow 1964; Kao and Stanfield 1968). The lyotropic series describes the degree of adsorbability of these anions on the membrane external surface that cause a change in the density of fixed charges (Hodgkin and Horowicz 1960; McLaughlin et al. 
1975), altering the surface potential and the potential gradient through the fibre membrane. Of particular importance is the chaotropic anion perchlorate, $\mathrm{ClO}_{4}^{-}$, that causes the largest change in the contractile threshold, potentiating manifold twitch tension (Foulks et al. 1973; Gomolla et al. 1983). A group of divalent heavy metals, such as $\mathrm{Zn}^{2+}, \mathrm{Be}^{2+}, \mathrm{Pt}^{4+}$ and others including uranil ions $\left(\mathrm{UO}_{2}\right)^{2+}$, also act as twitch potentiators, by a selective block of the $\mathrm{K}^{+}$conductance, that prolongs the duration of the AP, overcoming the nonspecific effects due to their adsorbability on the surface membrane (Sandow and Isaacson 1966). Sandow et al. (1965) proposed that both types of compounds enhanced the twitch, by prolonging a parameter, called the mechanically effective period (MEP), defined as the period during which the AP causes the release of an amount of $\mathrm{Ca}^{2+}$, greatly exceeding that necessary for a twitch response (Sandow 1964). MEP is increased either by lowering the contractile threshold (type A potentiators, like the lyotropic anions), or by prolonging the AP (type B potentiators, like the divalent heavy metals $\mathrm{Zn}^{2+}$, $\mathrm{Cd}^{2+}$, etc.). Other compounds, like caffeine, quinine and quinidine, that also potentiated contraction, were initially classified as type $\mathrm{C}$, since they seemed to act by a combination of both type A and type B mechanisms (Sandow 1964), but later, however, they were classified as type A, due to their sizeable effect on the contractile threshold. In all cases, prolongation of the active state could explain twitch potentiation, according to the classical view as type A potentiators (Hill 1949; Sandow 1965). While the prolongation of the AP remains the undiscussed mechanism of action for type B potentiators, the mechanism of action of type A potentiators requires some revision, in view of the increased knowledge about ECC. Nowadays, it is generally accepted that, in skeletal muscle, $\mathrm{Ca}^{2+}$ release from the SR is triggered by the mechanisms described in "The excitation-contraction coupling (ECC) mechanism in skeletal muscle".

The demonstration that lyotropic anions had similar effects on intramembrane charge movement and $\mathrm{ICa}^{2+}$ supported the idea that the DHPR serve as voltage sensor for ECC (Ríos and Brum 1987; Delay et al. 1990). In contrast, $\mathrm{ClO}_{4}$ at concentrations lower than $10 \mathrm{mM}$ selectively affected charge movement and contractile activation, without affecting activation of the AP (Ina) and activation of the delayed rectifier (Ik). SCN, the most potent of the lyotropic anion series, was found to be less selective than $\mathrm{ClO}_{4}^{-}$. In frog muscle fibres, $\mathrm{NO}_{3}$ and $\mathrm{Zn}^{2+}$ greatly increase the amplitude and duration of both $\mathrm{Ca}^{2+}$ transient and contractile responses while caffeine at $1 \mathrm{mM}$ potentiates twitch amplitude, without affecting the response time course (Caputo and Bolaños, unpublished). In mammalian fibres, $\mathrm{Ca}^{2+}$ transients are potentiated in a similar way by lyotropic anions, while the effect of caffeine is much less robust.

With respect to caffeine, and other alkaloids, including ryanodine, it was known that, depending on the concentration, they could potentiate twitches or induce contractures by interacting directly with the RyR (Lüttgau and Oetliker 1968; Weber and Herz 1968). In amphibian skeletal muscle, two isoforms of RyR are expressed in similar amounts, RyR1 and RyR3. While RyR1 is strictly located in the triadic junctional region, RyR3 has also been found in the extrajunctional region. Thus, in frog muscle fibres, due to the alternate disposition of RyR and DHPR, half of the RyR located in the junctional region, plus the amount located extrajunctionally, are not coupled to DHPR, suggesting a different gating mechanism. Evidence has been obtained indicating that caffeine directly acts on the latter channels that serve as target for voltage-independent activation.

In mammalian muscle, RyR3 is only expressed during post-natal development, almost disappearing in adult animals, except for the case of few muscles, like diaphragm and soleus, possibly explaining why caffeine is much less effective than in amphibian muscles. In support of this possibility, it was shown that responses to caffeine decreased during mice post-natal development and in adult animals caffeine remained effective only in those muscles as soleus and diaphragm that contained RyR3 (Rossi et al. 2001).

In conclusion, contractile potentiators have provided valuable insight into the mechanisms pertaining ECC, such as the role of DHPR as the voltage sensors for ECC. More recently, they are helping in understanding the differential functional significance of RyR1 and RyR3.

\section{Role of mitochondria in the ECC mechanism}

Mitochondria are organelles present in most cell types, in variable number, depending on the metabolic function and energetic needs of the tissue. The development of new techniques such as electron microscopy 3D reconstructions, tomography, CLSM, targeted mitochondria fluorescent probes (i.e. GFP-fusion proteins), and other molecular biology techniques, have provided copious information on mitochondria structure, organization and relationship with other subcellular organelles such as the SR. In this section, besides presenting recent evidence about muscle mitochondria relationship with the SR, we have also aimed at covering mitochondrial channels and inward $\mathrm{Ca}^{2+}$ transport as part of a more complex ECC sequence.

The outer mitochondrial membrane (OMM), although traditionally considered freely permeable, is a critical determinant for the mitochondrial $\mathrm{Ca}^{2+}$ accumulation. Nowadays, it is known that $\mathrm{Ca}^{2+}$ import across the OMM occurs through a Voltage Dependent Anionic Channel (VDAC), first described by Schein et al. (1976), and later identified as a porin of 30kDa (Zalman et al. 1980; Mannella et al. 1983; Rizzuto et al. 2009). Increased expression of VDAC enhances $\mathrm{Ca}^{2+}$ signal propagation into the mitochondria increasing the extent of mitochondrial $\mathrm{Ca}^{2+}$ uptake (Rapizzi et al. 2002). 
The inner membrane (IMM) is semi-permeable and highly selective; besides containing all the machinery for oxidative phosphorylation, it also contains $\mathrm{Ca}^{2+}$ channels and transporters. The discovery of the electron chain transport and the chemiosmotic hypothesis formulation by Mitchell and Moyle (1967) led to the proposal that $\mathrm{Ca}^{2+}$ uptake was mediated by a $\mathrm{Ca}^{2+}$ channel, named Mitochondrial Calcium Uniporter (MCU), and driven by the large potential difference $(-150$ to $-180 \mathrm{mV})$ established by the electrogenic extrusion of protons (Kirichok et al. 2004; Baughman et al. 2011; De Stefani et al. 2011).

MCU is a low affinity/high capacity (Kd of $10-20 \mu \mathrm{M})$ oligomeric complex, identified as a highly selective $\mathrm{Ca}^{2+}$ channel (Gunter and Pfeiffer 1990; Gunter et al. 1994; Bernardi 1999; Kirichok et al. 2004) formed by a $40-\mathrm{kDa}$ protein with two transmembrane domains (Baughman et al. 2011; De Stefani et al. 2011). It was recently found that MCU of mitoplasts from skeletal muscle present higher conductance than from other tissues (Fieni et al. 2012). At rest, $\mathrm{Ca}^{2+}$ concentration in mitochondria and cytoplasm are similar, due to the activity of $\mathrm{Ca}^{2+}$ extruding systems and to the low activity of MCU under the normally low cytoplasmic $\mathrm{Ca}^{2+}$ conditions (Alonso et al. 2006). Because of its Kd, only when global $\mathrm{Ca}^{2+}$ rises above the micromolar level, the MCU is activated and a net uptake of $\mathrm{Ca}^{2+}$ by the mitochondria occurs, which is later slowly reversed, until reestablishment of the resting $\mathrm{Ca}^{2+}$ (Rizzuto and Pozzan 2006; Bolaños et al. 2009). The establishment of high $\mathrm{Ca}^{2+}$ microdomains around the sites of release by IP3R or RyR will favor the $\mathrm{Ca}^{2+}$ transport into mitochondria (Rizzuto et al. 1993; Rizzuto and Pozzan 2006; Drago et al. 2012).

A rapid mode of $\mathrm{Ca}^{2+}$ uptake (RaM) has been shown to occur in response to imposed $\mathrm{Ca}^{2+}$ signals in isolated liver and heart mitochondria (Sparagna et al. 1995; Bernardi 1999; Buntinas et al. 2001). The RaM activates transiently at the beginning of cytoplasmic $\mathrm{Ca}^{2+}$ pulses and is detectable above $200 \mathrm{nM}$ in isolated heart mitochondria (Sparagna et al. 1995; Bernardi 1999; Buntinas et al. 2001). An additional $\mathrm{Ca}^{2+}$ uptake inhibited by ryanodine indicates the presence of mRyR within the IMM. This channel, which shares several similar biochemical, pharmacological, and physiological properties with both the RyR and RaM (Beutner et al. 2001) have been identified as RyR1 (Beutner et al. 2005). Both uptake modes (RaM and mRyR) exhibit kinetics, $\mathrm{Ca}^{2+}$ dependence, and pharmacology that allow them to be distinguished from the MCU (Ryu et al. 2010, 2011).

Two different antiporter systems responsible for exporting or importing $\mathrm{Ca}^{2+}$ have been described in mitochondria, the NCX (mNCX) which shares properties with the classical NCX (Jung et al. 1995; Smets et al. 2004) and is expressed in excitable cells, and the $\mathrm{H} / \mathrm{Ca}^{2+}$ (mHCX) exchanger, present in non-excitable cells (Carafoli et al. 1974; Bernardi 1999; Jiang et al. 2009) and whose molecular identity is the Leucine zipper EF-hand transmembrane protein (Letm1). This protein allows mitochondrial $\mathrm{Ca}^{2+}$ uptake at nanomolar concentrations (Jiang et al. 2009).

Finally, the co-existence of low (MCU) and high-affinity (RaM, RyR and Letm1) modes of $\mathrm{Ca}^{2+}$ uptake into mitochondria, would allow different mitochondrial populations to take up different amounts of $\mathrm{Ca}^{2+}$ during cell activation, thus modulating $\mathrm{Ca}^{2+}$ signalling, depending on their location relative to $\mathrm{Ca}^{2+}$ stores and channels (Santo-Domingo and Demaurex 2010).

The permeability transient pore (PTP) (Hunter and Haworth 1979) is a large pore whose identity had remained elusive, and spans both IMM and OMM and is activated by $\mathrm{Ca}^{2+}$ overloading (Kinnally et al. 1989; Petronilli et al. 1989; Bernardi 1992, 1999; Saris and Carafoli 2005; Zoratti et al. 2005; Bernardi and von Stockum 2012). It can also operate as a $\mathrm{Ca}^{2+}$ release channel under physiological conditions (Bernardi and von Stockum 2012). Recently, it has been found that reconstituted dimers of the FoF1 ATP synthase form a channel with properties identical to those of the PTP (Giorgio et al. 2013).

In skeletal muscle, mitochondria occupy $10-15 \%$ of the fibre volume and are mainly located either peripherically in subsarcolemmal clusters or between myofibrils (Fig. 3), largely within the I-bands, surrounding the SR network (Gauthier and Padykula 1966; Eisenberg 1983). This structural arrangement is developmentally regulated, with mitochondria arranged in non-ordered longitudinal fashion in newborn mice (Boncompagni et al. 2009; Rossi et al. 2011). These intermyofibrillar mitochondria are highly organized in pairs at the I-band level, close to the CRU on either side of the Zline, between T-Tubules, and contacting the SR near sites of $\mathrm{Ca}^{2+}$ uptake by the SERCA (Ogata and Yamasaki 1985; Ramesh et al. 1998; Vendelin et al. 2005; FranziniArmstrong 2007; Bolaños et al. 2008). This arrangement favours fast ATP delivery to support $\mathrm{Ca}^{2+}$ transport into SR and to participate in $\mathrm{Ca}^{2+}$ homeostasis capturing $\mathrm{Ca}^{2+}$ from high $\mathrm{Ca}^{2+}$ microdomains near the sites of release (Rizzuto and Pozzan 2006; Shkryl and Shirokova 2006; FranziniArmstrong 2007; Rossi et al. 2011; Yi et al. 2011; Drago et al. 2012). Subsarcolemmal mitochondria are organized in clusters, densely packed and less regularly arranged as compared with intermyofibrillar ones (Ogata and Yamasaki 1985; Kuznetsov et al. 2006). Skeletal muscle fibre types show differences in their mitochondria content being higher in slow-twitch fibres (Gauthier and Padykula 1966; Ogata and Yamasaki 1985), as well as morphological and functional diversity, existing specialisation in function between mitochondria from both slow-oxidative and fast-glycolitic fibre types (Kuznetsov et al. 2006; Picard et al. 2012).

The close proximity of mitochondria to the SR and calcium release units has been studied in many preparations using many techniques (Franke and Kartenbeck 1971; Morre et al. 1971; Lewis and Tata 1973; Shore and Tata 1977; Meier et al. 
Fig. 3 Subsarcolemmal (left) and inner $(r i g h t)$ differential

mitochondrial distribution in flexor digitorum brevis muscle fibres stained with Mitotracker Green. The images were acquired with a Nikon C1 confocal microscope. A pattern of paired columns of mitochondria, parallel to the short axis of the cell, can be identified in the inner or intermyofibrillar location, while single, longer rows of mitochondria, parallel to the long axis of the cell, can be identified in the subsarcolemmal region of the cell
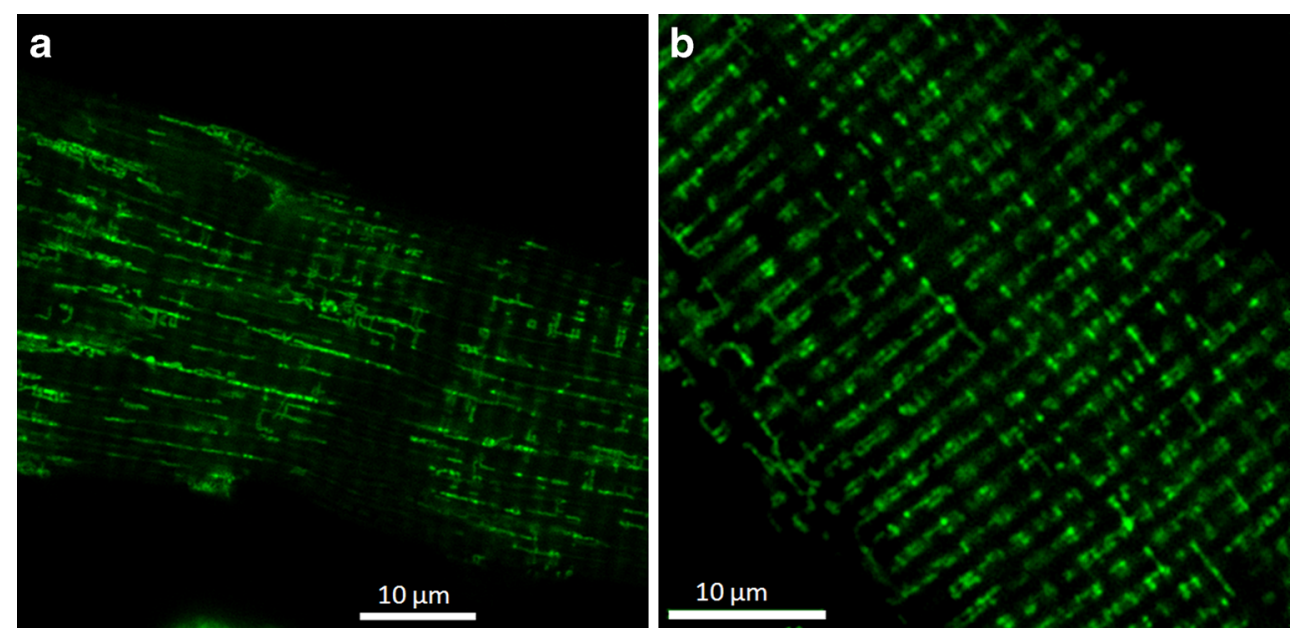

1981; Mannella et al. 1998; Franzini-Armstrong and Boncompagni 2011). It was shown that as much as $20 \%$ of the mitochondrial surface is in direct contact with the ER (Rizzuto et al. 1998) and that the maintenance of a proper spacing between ER and mitochondria seems to guarantee cell function and survival in some tissues (Csordás et al. 2006). In mouse FDB muscle fibres, strands of 3-4 nm diameter and 9$10 \mathrm{~nm}$ length (Franzini-Armstrong 2007; Boncompagni et al. 2009) appear to anchor mitochondria to the SR. The number of these tethers increases during postnatal development and might restrict mitochondrial movement away from sites of SR $\mathrm{Ca}^{2+}$ release, especially during contractile movements and shortening (Boncompagni et al. 2009; Rossi et al. 2011), providing a structural framework for bidirectional SRmitochondrial signalling (Dirksen 2009b). In adult skeletal muscle, since mitochondria are anchored on the far side of the triads a diffusional distance of about $\sim 130 \mathrm{~nm}$ separates the release sites from mitochondria (Franzini-Armstrong 2007), and a dissipation of $\mathrm{Ca}^{2+}$ microdomains could occur (Stern 1992). However, in developing muscle, this distance can be less than $100 \mathrm{~nm}$ and mitochondria could experience a significant $\mathrm{Ca}^{2+}$ release microdomain (Rossi et al. 2011).

Although the exact nature of tethers remains unresolved, it has been proposed that they are formed by a complex termed the "ER-mitochondria encounter complex" (ERMES), involving several proteins present in the OMM and in the ER that appear essential to keep the contact points between the two organelles in yeast (Kornmann et al. 2009). In mammals, silencing mitofusin disrupts ER morphology and loosens ERmitochondria interactions, thereby reducing the efficiency of mitochondrial $\mathrm{Ca}^{2+}$ uptake in response to stimuli (de Brito and Scorrano 2008; see Eisner et al. 2013).

Mitochondrial $\mathrm{Ca}^{2+}$ uptake has been shown to occur during electrically elicited contractile responses in mouse muscle fibres, with a relatively short delay, $10 \mathrm{~ms}$, between the $\mathrm{Ca}^{2+}$ signal in the myoplasm and that in the mitochondria (Rudolf et al. 2004; Yi et al. 2011). Transgenic mice expressing the
$\mathrm{Ca}^{2+}$-sensitive bioluminescent reporter GFP-aequorin targeted to the mitochondrial matrix were studied in mice in vivo and showed a readily detected rapid $\mathrm{Ca}^{2+}$ rise inside the mitochondrial matrix during single-twitch muscle contractions (Rogers et al. 2007). In both slow- and fast-twitch fibres from rat, mitochondria are capable of accumulating $\mathrm{Ca}^{2+}$ in the presence of BAPTA that suppress $\mathrm{Ca}^{2+}$ transients but not mitochondrial $\mathrm{Ca}^{2+}$ increases, suggesting some kind of $\mathrm{Ca}^{2+}$ tunnelling from SR to mitochondria (Shkryl and Shirokova 2006).

In muscle cell lines and myotubes, mitochondria can pick up $\mathrm{Ca}^{2+}$ mobilised from a single RyR release unit (sparks) leading to the generation of single mitochondrial miniature $\mathrm{Ca}_{\text {myt }}$ signals $\left(\mathrm{Ca}^{2+}\right.$ marks $)$ and to feedback control on the $\mathrm{Ca}^{2+}$ release (Pacher et al. 2002; Isaeva et al. 2005).

Inhibition of mitochondrial $\mathrm{Ca}^{2+}$ uptake, either by blocking $\mathrm{MCU}$ with ruthenium red or by dissipating the mitochondrial membrane potential with protonophores like Carbonyl cyanide 4-trifluoromethoxy phenylhydrazone (FCCP), results in a large cytoplasmic $\mathrm{Ca}^{2+}$ increase with a slow rate of recovery (Rizzuto et al. 2000; Caputo and Bolaños 2008). In mice FDB muscle fibres, poisoning the mitochondria with FCCP (Fig. 4) causes a sizeable and rapid increase in the basal $\mathrm{Ca}^{2+}$ concentration followed by a marked decrease of Mag-Fluo- $4 \mathrm{Ca}^{2+}$ transients, and variable effects on the time course of $\mathrm{Ca}^{2+}$ transient decay, probably related to the composition of fibre types in FDB fibres (Caputo and Bolaños 2008; Calderón et al. 2009). $\mathrm{Ca}^{2+}$ uptake by mitochondria has also been observed in mice FDB fibres loaded with Rhod-2 and subjected to a SR depletion procedure to study SOCE (Fig. 5) or $\mathrm{Ca}^{2+}$ release in FDB fibres loaded with CaOrange- $5 \mathrm{~N}$ and exposed to the protonophore $\mathrm{FCCP}$ (Bolaños et al. 2008, 2009).

$\mathrm{Ca}^{2+}$ mitochondria uptake after contractile activation during repetitive tetanic stimulation in toad and mouse fibres is reduced by FCCP poisoning (Lännergren et al. 2001; Bruton et al. 2003). In PV knockout mouse, the muscle fibres content of mitochondria doubles and the fibres appear to have an increased resistance to fatigue. The increased mitochondrial 
Fig. 4 Time course of fluorescence decay after FCCP poisoning (right), in one flexor digitorum brevis fibre stained with TMRE to visualize mitochondrial potential ( $\Psi \mathrm{m})$. On the left, confocal images of the cell indicating regions of interest (ROI, numbered squares) and time of acquisition after starting the experiment are shown. On the right, the black squares represent the mean \pm SEM of the measurements carried out at level of the ROI as a function of time. A rapid decrease in fluorescence, suggesting a dissipation of $\Psi \mathrm{m}$, is seen after the application of FCCP
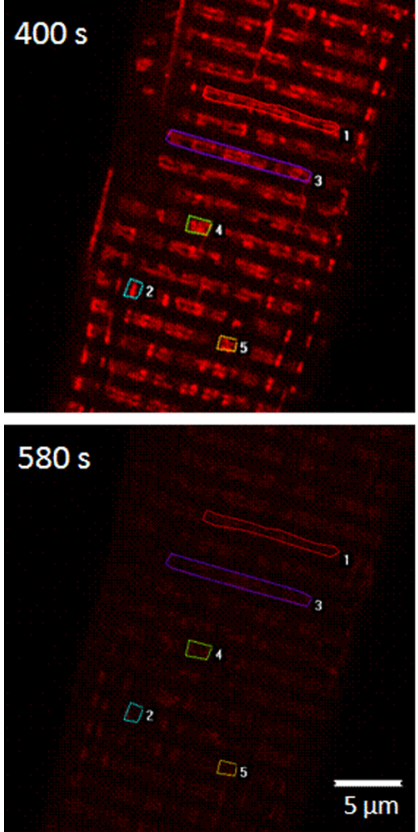

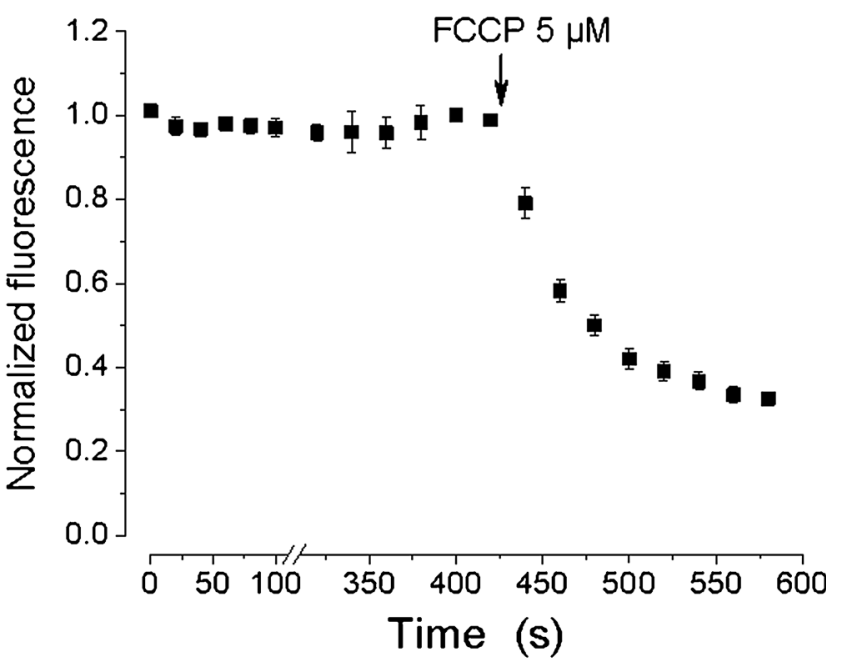

content results in a faster than expected removal of $\mathrm{Ca}^{2+}$ following brief tetanic stimulation (Racay et al. 2006).

Even when it is clear that mitochondria have a role in $\mathrm{Ca}^{2+}$ regulation during ECC and during contractile activity, their physiological relevance for different fibre types is not clear. Some have claimed that mitochondria may be relevant mainly in slow-twitch fibres, but others have not seen differential effect of blocking mitochondrial $\mathrm{Ca}^{2+}$ uptake in slow- and

fast-twitch fibres during a tetani (Gillis 1997; Sembrowich et al. 1985; Lännergren et al. 2001; Calderón et al., unpublished results).

Future work may address the details of the SR-mitocondrial communication in skeletal muscle, and the tethers nature, considering also different fibre types, differences between subsets of mitochondria in skeletal muscle and different conditions such as fatigue, ageing and diseases. a

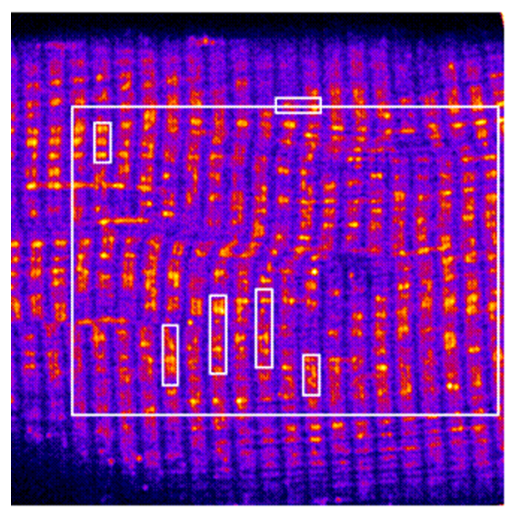

$10 \mu \mathrm{m}$ b

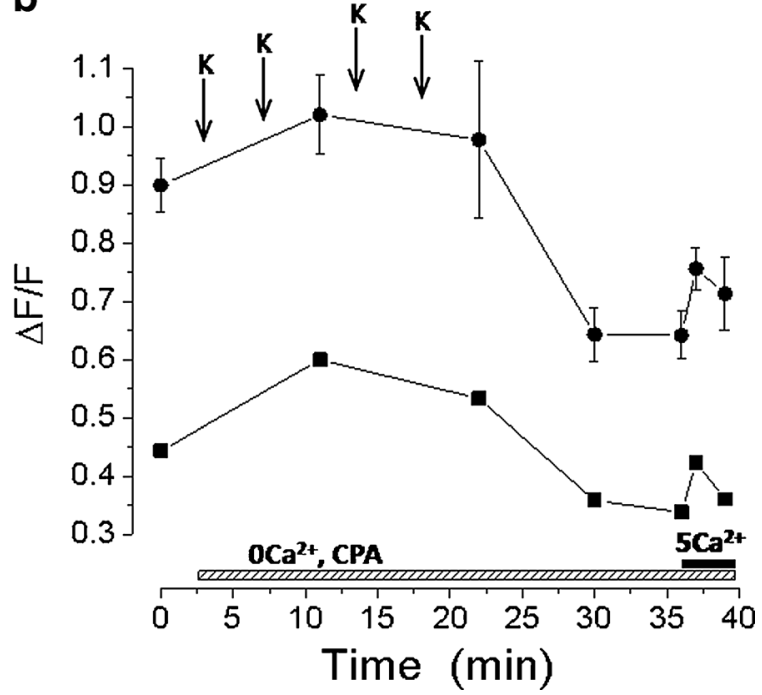

square in (a). The mitochondrial fluorescence increases during the protocol in which the cell is in absence of external $\mathrm{Ca}^{2+}$ and the SR $\mathrm{Ca}^{2+}$ ATPase is blocked by cyclopiazonic acid (CPA). When $5 \mathrm{mM} \mathrm{Ca}^{2+}$ external solution reaches the cell the mitochondria uptake part of the $\mathrm{Ca}^{2+}$ entering the fibre via the store operated $\mathrm{Ca}^{2+}$ entry mechanism. $K$ indicates the moments in which an external solution with high $\mathrm{K}^{+}$concentration was applied to elicit $\mathrm{SR} \mathrm{Ca}^{2+}$ release in order to deplete this $\mathrm{Ca}^{2+}$ store 


\section{SOCE-mitochondria-ECC relationship}

SOCE was originally described in non-excitable cells, where it constitutes a major pathway for $\mathrm{Ca}^{2+}$ influx. It was denominated capacitative calcium influx $\left(\mathrm{I}_{\mathrm{CRAC}}\right)$ and characterised as a very small but highly $\mathrm{Ca}^{2+}$ selective current that insures the replenishment of the ER (Putney 1986; Hoth and Penner 1992; Parekh and Putney 2005).

SOCE has also been demonstrated in excitable cells (Bernardi 1999; Rizzuto et al. 2000; Parekh and Putney 2005) as adult skeletal muscle fibres (Kurebayashi and Ogawa 2001; Ma and Pan 2003; Ducret et al. 2006; Gonzalez Narvaez and Castillo 2007; Launikonis and Ríos 2007; Bolaños et al. 2009; Dirksen 2009a), though there is less information on the regulatory mechanisms involved in SOCE activation in excitable cells, in particular adult skeletal muscle fibres, than in non-excitable cells.

The molecules involved in the SOCE complex have been identified. The first one, the stromal interacting molecule STIM1, present in the ER/SR membrane, senses the degree of filling of $\mathrm{Ca}^{2+}$ in the ER/SR (Liou et al. 2005; Roos et al. 2005; Zhang et al. 2005). The second, Orail, has been identified as the conductive pore sub-unit of the $\mathrm{I}_{\mathrm{CRAC}}$ channel (Feske et al. 2006; Prakriya et al. 2006; Vig et al. 2006). In mammals, two STIM genes and three Orai genes have been identified (Zhang et al. 2005; Feske et al. 2006; Vig et al. 2006). When $\mathrm{Ca}^{2+}$ levels are low, STIM1 clusters in regions of the ER/plasma membrane junctions denominated punctae, where it interacts with Orail activating $\mathrm{Ca}^{2+}$-influx (Luik et al. 2006; Smyth et al. 2006; Soboloff et al. 2006; Muik et al. 2009). In endothelial cells exposed to FCCP and/or oligomicin, STIM1-Orai1-dependent SOCE is completely prevented, thus pointing to an essential contribution of mitochondrial $\mathrm{Ca}^{2+}$ handling to STIM1-Orai1-dependent SOCE. These finding suggest that a $\mathrm{Ca}^{2+}$-dependent process in the mitochondria unlike (or in addition to) local $\mathrm{Ca}^{2+}$ buffering is essential and specific for the activity of the STIM1-Oraildependent SOCE (Naghdi et al. 2010).

In skeletal muscle, STIM1 and Orail are highly expressed (Stiber et al. 2008; Vig et al. 2008) and are localized at triadic level and in the SR terminal cisternae. In this tissue, SOCE activation and deactivation is in the order of milliseconds indicating that STIM1 and Orail must be evenly distributed throughout the junctional membrane and can activate rapidly (Launikonis and Ríos 2007; Stiber et al. 2008; Edwards et al. 2010). Two models that allow for rapid SOCE activation upon SR $\mathrm{Ca}^{2+}$-store depletion were proposed by Dirksen (2009a). The first one states that STIM1 monomers are prelocalized at SR terminal cisternae in the vicinity of inactive Orail channels at the triadic junctions. When $\mathrm{Ca}^{2+}$ dissociates from STIM1, in response to SR depletion, their conformational change and oligomerization will permit the activation of Orail also prelocalized in the T-tubule membrane. The second model proposes that STIM1/Orail complex exists preformed but inactive until $\mathrm{SR} \mathrm{Ca}^{2+}$ depletion reaches a certain level, triggering direct activation of Orail-mediated $\mathrm{Ca}^{2+}$ influx. This last possibility would allow an ultrafast, very efficient and controlled activation of $\mathrm{Ca}^{2+}$ influx through Orail (Launikonis and Ríos 2007; Dirksen 2009a; Edwards et al. 2010).

Though it seems that SOCE has no physiological role in skeletal muscle short-term activation, and it is not required to refill SR (Cully and Launikonis 2013) $\mathrm{Ca}^{2+}$ entry through SOC is crucial for long-term $\mathrm{Ca}^{2+}$ homeostasis, such that reduced SOC activity exaggerates muscle fatigue under conditions of intensive exercise (Pan et al. 2002).

In FDB adult mouse skeletal muscle fibres, FCCP mitochondria poisoning increases the $\mathrm{Ca}^{2+}$ myoplasmic levels, reduces the amplitude of $\mathrm{Ca}^{2+}$ transients and reduces SOCE (Fig. 6) (Bolaños et al. 2008, 2009; Caputo and Bolaños 2008). This effect has been explained in terms of different mechanisms: (1) reduction of $\mathrm{Ca}^{2+}$ uptake by mitochondria increases cytoplasmic $\mathrm{Ca}^{2+}$, thus favouring $\mathrm{Ca}^{2+}$ dependent inactivation of the SOC channels (Hoth et al. 2000); (2) removal of mitochondrial competition with SERCA pumps that favors store replenishment (Parekh 2003); and (3) inhibition of some factor produced by functional mitochondria necessary for SOCE activation (Glitsch et al. 2002; Naghdi et al. 2010). The close functional relationship between SR and mitochondria (Isaeva and Shirokova 2003; Shkryl and Shirokova 2006; Bolaños et al. 2008; Boncompagni et al. 2009; Rossi et al. 2011) facilitates the establishment of microdomains (Rizzuto et al. 1993; Berridge 2006; Rizzuto and Pozzan 2006) and the uptake of $\mathrm{Ca}^{2+}$ by mitochondria immediately after its release from the SR or the influx through SOCs, before it can diffuse out the restricted space of the SR-mitochondrial junctions.

In spite of recent studies claiming that SOCE is not relevant in skeletal muscle for SR $\mathrm{Ca}^{2+}$ replenishment (Cully and Launikonis 2013), all the machinery needed to activate it is present at the triad. On the other hand, it is known that SOCE activation requires fully energized mitochondria in excitable and non-excitable tissues (Glitsch et al. 2002; Bolaños et al. 2009; Naghdi et al. 2010). Future work must be addressed to clarify not only the physiological relevance of SOCE but also its modulation by mitochondria and/or other components involved in ECC in skeletal muscle.

$\mathrm{Ca}^{2+}$ sparks

$\mathrm{Ca}^{2+}$ sparks were first described as minute, spontaneous fluorescence signals originating from highly restricted zones of cardiac myocytes (Cheng et al. 1993). They could also be elicited, at a much higher frequency, by cell membrane depolarization. The occurrence of the events did not depend on external $\mathrm{Ca}^{2+}$ or on $\mathrm{Ca}^{2+}$ entry through the L-type $\mathrm{Ca}^{2+}$ channels. The properties of the sparks, and the localization 
Fig. 6 Activation of storeoperated $\mathrm{Ca}^{2+}$ entry (SOCE) in a flexor digitorum brevis fibre loaded with Fura-2 after sarcoplasmic reticulum (SR) depletion by high $\mathrm{K}^{+}$exposures in the absence of external $\mathrm{Ca}^{2+}$ and in the presence of thapsigargin (TG) 5-10 $\mu \mathrm{M}$. a Once depleted as shown by the absence of response to high $\mathrm{K}^{+}, \mathrm{Ca}^{2+}$ reintroduction in the external medium activates SOCE. The $\mathrm{Ca}^{2+}$ entrance can be reversibly blocked by $80 \mu \mathrm{M}$ 2-APB. b When a similar protocol is applied to another fibre, but exposed to FCCP, SOCE cannot be activated again. It can be partially recovered after a long washout of the drug. This suggests that the mitochondrial depolarization affects the $\mathrm{Ca}^{2+}$ entry induced by SR depletion
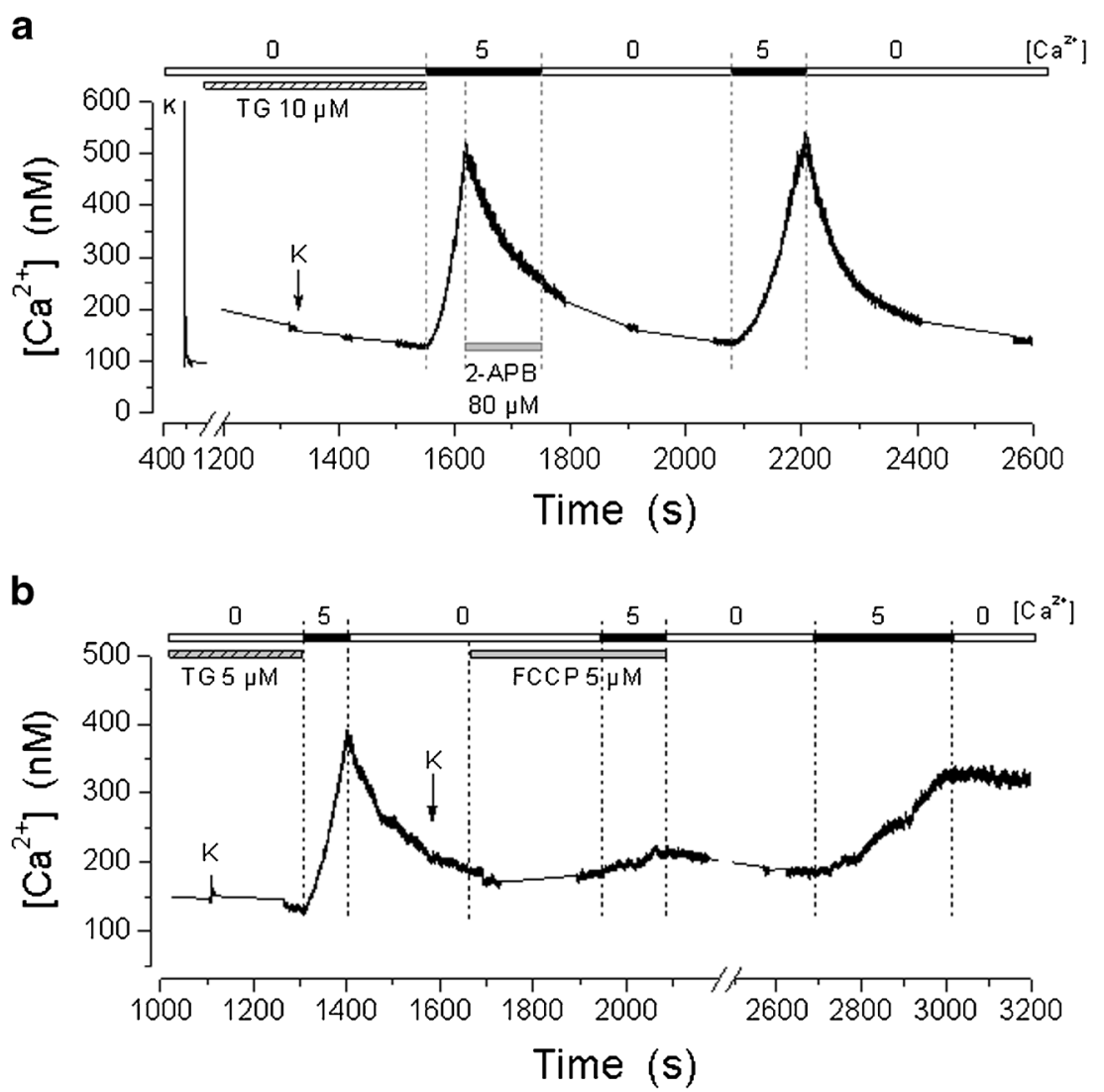

of their origin, at the level of the junctional region between SR and T-tubules, led to the conclusion that they derived from point $\mathrm{Ca}^{2+}$ sources, and constituted the elementary $\mathrm{Ca}^{2+}$ release events for ECC, resulting from the transient openings of $\mathrm{Ca}^{2+}$ release channels. In the heart, these channels were identified as the RyR2, activated via a CICR mechanism, by $\mathrm{Ca}^{2+}$ entering the myocytes through the DHPR (Cheng and Lederer 2008).

$\mathrm{Ca}^{2+}$ sparks were also demonstrated in amphibian striated muscle fibres (Tsugorka et al. 1995), where they could occur spontaneously or be evoked by membrane depolarization; in both cases, their spatio-temporal characteristics were similar and were not affected by the level of the membrane potential in the range from -80 and $+40 \mathrm{mV}$ (LaCampagne et al. 1996). The frequency of spark generation was potential-dependent and could be modulated by $\mathrm{Ca}^{2+}$ that increased it and $\mathrm{Mg}^{2+}$ that had the opposite effect (Zhou et al. 2004).

Contrary to the initial idea that one spark corresponded to the opening of a single release channel, Shtifman et al. (2000) estimated the number of release channels contributing to the generation of one event to be between 2 and 4 . Moreover, the idea that one spark represented one quantum of $\mathrm{Ca}^{2+}$ release was also challenged by the demonstration of diffused $\mathrm{Ca}^{2+}$ release, not associated with defined sparks, both in cardiac (Lipp and Niggli 1996) and in skeletal (Shirokova and Ríos 1997) muscle fibres.
Also in skeletal muscle, $\mathrm{Ca}^{2+}$ sparks occur at level of the triadic junctional region (see "The excitation-contraction coupling (ECC) mechanism in skeletal muscle"). Due to the alternate disposition of the RyR and DHPR arrays, for each tetrameric molecule facing, and under control of, a tetrad, there is one molecule that is not. Furthermore, the presence of another RyR isoform, RyR3, that forms arrays in the extrajunctional regions of amphibian skeletal muscle fibres, increases the fraction of $\mathrm{Ca}^{2+}$ release channels that are not under control of the DHPR (Felder and Franzini-Armstrong 2002).

Opposite to the case of frog muscles, $\mathrm{Ca}^{2+}$ sparks are rarely observed in mammalian muscle under physiological conditions. Instead, release events not composed of $\mathrm{Ca}^{2+}$ sparks were observed in response to membrane depolarization or exposure to caffeine leading to the proposal that in rats this release was the unique response to voltage activation, while in frog the initial release events served as a trigger for CICR responses visualised as sparks. The idea that RyR3 was associated with spark generation in amphibian was proved correct by the demonstration that exogenous expression of RyR3 in adult mouse muscle caused an abundance of sparks in response to depolarisation, changing a spark-free mammalian response, into a frog one (Pouvreau et al. 2007b).

On the other hand, in mammalian muscle, $\mathrm{Ca}^{2+}$ sparks could be observed under special conditions, such as permeabilization by saponine, osmotic stress, membrane damage 
and mitochondrial metabolic uncoupling (Apostol et al. 2009; Weisleder 2012; Isaeva and Shirokova 2003), demonstrating that the machinery and capacity for spark generation are present in mammalian muscle, but somehow repressed. In favour of this view, it has been shown that, during myotubes differentiation, the presence of T-tubules determine the absence of $\mathrm{Ca}^{2+}$ sparks and of RyR1 and RyR3, that abound where T-tubules are not present (Zhou et al. 2006).

Although the specific mechanisms by which RyR1 and RyR3 operate have not yet been clarified, there is strong evidence pointing to the importance of RyR3 in determining the mode of $\mathrm{Ca}^{2+}$ release.

\section{Perspectives}

Some tasks still remain to gain full knowledge on ECC. The search for new minor ECC proteins (Treves et al. 2009) and to study their role in fatigue, ageing and diseases, as well as their variability according to fibre types, should continue. The application of ECC knowledge is of paramount importance to fight muscle diseases and help in conditions such as ageing (Wang et al. 2012; Mosca et al. 2013). To develop a mathematical model on ECC that integrates most of the recent information gathered on ECC under different conditions will allow us to better understand and manipulate $\mathrm{Ca}^{2+}$ kinetics. Also, a better understanding of the relationsip between ECC machinery and muscle biochemical and metabolic functions (besides the production of ATP) is an important endeavor that deserves full attention in the coming years. Considering that many RyR are not directly coupled to DHPR, and that CICR is not operational in mammalian muscle under physiological conditions, the puzzle that remains to be solved is whether and how the DHPR-coupled RyR signal the uncoupled ones to synchronize $\mathrm{Ca}^{2+}$ release. In addressing many of these questions it is likely that the use of super-resolution microscopy and the improvement of its time-resolution will allow for a new era of physiological studies.

\section{Conclusions}

In conclusion, the ECC mechanism represents a rapid communication between electrical events occurring in the plasma membrane and the $\mathrm{Ca}^{2+}$ release from the SR, which leads to skeletal muscle contraction. A large body of knowledge on the concerted function of the main macromolecules and some minor molecules involved in ECC mechanism has been gathered as a result of six decades of research. Additionally, ECC understanding will benefit from the continuous gain in temporal and spatial resolution of most of the techniques currently used for ECC study. The application of the knowledge gathered on ECC will likely help understand the pathophysiology of some muscle diseases and develop tools to fight them.
Acknowledgments The financial support comes from University of Antioquia, Medellín, Colombia (J.C.C.) and Venezuelan Institute for Scientific Research, Venezuela (P.B. and C.C.). We want to acknowledge Alis Guillén for help in obtaining some experimental results presented in this review and Carolina Figueroa por sharing some information with us.

Conflict of interest Juan C. Calderón, Pura Bolaños and Carlo Caputo declare that they have no conflict of interest.

Human and animal studies This article does not contain any studies with human or animal subjects performed by any of the authors.

\section{References}

Abbiss C, Laursen P (2005) Models to explain fatigue during prolonged endurance cycling. Sports Med 35:865-898

Adams B, Tanabe T, Mikami A, Numa S, Beam K (1990) Intramembrane charge movement restored in dysgenic skeletal muscle by injection of dihydropyridine receptor cDNAs. Nature 346:569-572

Adrian R, Costantin L, Peachey L (1969) Radial spread and contraction in frog muscle fibres. J Physiol 204:231-257

Allen D, Lee J, Westerblad H (1989) Intracellular calcium and tension during fatigue in isolated single muscle fibres from Xenopus laevis. J Physiol 415:433-458

Allen D, Lännergren J, Westerblad H (1997) The role of ATP in the regulation of intracellular $\mathrm{Ca}^{2+}$ release in single fibres of mouse skeletal muscle. J Physiol 498:587-600

Allen D, Lännergren J, Westerblad H (2002) Intracellular ATP measured with luciferin/luciferase in isolated single mouse skeletal muscle fibres. Pflugers Arch 443(5-6):836-842

Allen D, Lamb G, Westerblad H (2008) Skeletal muscle fatigue: cellular mechanisms. Physiol Rev 88:287-332

Alonso M, Villalobos C, Chamero P, Alvarez J, Garcia-Sancho J (2006) Calcium microdomains in mitochondria and nucleus. Cell Calcium 40:513-525

Anderson A, Altafaj X, Zheng Z, Wang Z, Delbono O, Ronjat M et al (2006) The junctional SR protein JP-45 affects the functional expression of the voltage-dependent $\mathrm{Ca}^{2+}$ channel Cav1.1. J Cell Sci 119:2145-2155

Apostol S, Ursu D, Lehmann-Horn F, Melzer W (2009) Local calcium signals induced by hyper-osmotic stress in mammalian skeletal muscle cells. J Muscle Res Cell Motil 30:97-109

Appelt D, Buenviaje B, Champ C, Franzini-Armstrong C (1989) Quantitation of "junctional feet" content in two types of muscle fiber from hind limb muscles of the rat. Tissue Cell 21:783-794

Armstrong C, Bezanilla F, Horowitz P (1972) Twitches in the presence of ethylene glycol bis(-aminoethyl ether)-N, N'-tetracetic acid. Biochim Biophys Acta 267:605-608

Ávila G, Dirksen R (2000) Functional impact of the ryanodine receptor on the skeletal muscle L-type $\mathrm{Ca}^{2+}$ channel. J Gen Physiol 114:467-480

Axelsson J, Thesleff S (1958) Activation of the contractile mechanism in striated muscle. Acta Physiol Scand 44:55-66

Balnave C, Allen D (1998) Evidence for $\mathrm{Na}+/ \mathrm{Ca} 2+$ Exchange in intact single skeletal muscle fibers from the mouse. Am J Physiol Cell Physiol 274:940-946

Bangsbo J, Juel C (2006) Lactic acid accumulation is a disadvantage during muscle activity. J Appl Physiol 100:1412-1413

Bär A, Pette D (1988) Three fast myosin heavy chains in adult rat skeletal muscle. FEBS Lett 235:153-155

Barclay J, Hansel M (1991) Free radicals may contribute to oxidative skeletal muscle fatigue. Can J Physiol Pharmacol 69:279-284

Baughman JM, Perocchi F, Girgis HS, Plovanich M, Belcher-Timme CA, Sancak Y, Bao XR, Strittmatter L, Goldberger O, Bogorad RL, 
Koteliansky V, Mootha VK (2011) Integrative genomics identifies MCU as an essential component of the mitochondrial calcium uniporter. Nature 476:341-345

Baylor S, Hollingworth S (1988) Fura-2 calcium transients in frog skeletal muscle fibres. J Physiol 403:151-192

Baylor S, Hollingworth S (2003) Sarcoplasmic reticulum calcium release compared in slow-twitch and fast-twitch fibres of mouse muscle. J Physiol 551:125-138

Baylor S, Hollingworth S (2011) Calcium indicators and calcium signalling in skeletal muscle fibres during excitation-contraction coupling. Prog Biophys Mol Biol 105:162-179

Beam K, Franzini-Armstong C (1997) Functional and structural approaches to the study of excitation-contraction coupling. Methods Cell Biol 52:283-306

Beam K, Knudson C, Powell J (1986) A lethal mutation in mice eliminates the slow calcium current in skeletal muscle cells. Nature 320: $168-170$

Bekoff A, Betz W (1977) Physiological properties of dissociated muscle fibres obtained from innervated and denervated adult rat muscle. J Physiol 271:25-40

Bergström M, Hultman E (1988) Energy cost and fatigue during intermittent electrical stimulation of human skeletal muscle. J Appl Physiol 65:1500-1505

Bernardi P (1992) Modulation of the mitochondrial cyclosporin A-sensitive permeability transition pore by the proton electrochemical gradient. Evidence that the pore can be opened by membrane depolarization. J Biol Chem 267:8834-8839

Bernardi P (1999) Mitochondrial transport of cations: channels, exchangers, and permeability transition. Physiol Rev 79:1127-1155

Bernardi P, von Stockum S (2012) The permeability transition pore as a $\mathrm{Ca}(2+)$ release channel: new answers to an old question. Cell Calcium 52:22-27

Berridge M (2006) Calcium microdomains: organization and function. Cell Calcium 40:405-412

Beutner G, Sharma V, Giovannucci D, Yule D, Sheu S (2001) Identification of a ryanodine receptor in rat heart mitochondria. J Biol Chem 276:21482-21488

Beutner G, Sharma V, Lin L, Ryu S, Dirksen R, Sheu S (2005) Type 1 ryanodine receptor in cardiac mitochondria: transducer of excitation-metabolism coupling. Biochim Biophys Acta 1717:1-10

Bezanilla F (2000) The voltage sensor in voltage-dependent ion channels. Physiol Rev 80:555-592

Bezanilla F, Caputo C, González-Serratos H, Venosa R (1972) Sodium dependence of the inward spread of activation in isolated twitch muscle fibres of the frog. J Physiol 223:507-523

Bigland-Ritchie B, Woods J (1984) Changes in muscle contractile properties and neural control during human muscular fatigue. Muscle Nerve 7:691-699

Bleunven C, Treves S, Jinyu X, Leo E, Ronjat M, De Waard M et al (2008) SRP-27 is a novel component of the supramolecular signaling complex involved in skeletal muscle excitation-contraction coupling. Biochem J 411:343-349

Block B, Imagawa T, Campbell K, Franzini-Armstrong C (1988) Structural evidence for direct interaction between the molecular components of the transverse tubule/sarcoplasmic reticulum junction in skeletal muscle. J Cell Biol 107:2587-2600

Bolaños P, Guillén A, Rojas H, Boncompagni S, Caputo C (2008) The use of CalciumOrange- $5 \mathrm{~N}$ as a specific marker of mitochondrial $\mathrm{Ca}^{2+}$ in mouse skeletal muscle fibers. Pflugers Arch 455:721-731

Bolaños P, Guillén A, DiPolo R, Caputo C (2009) Factors affecting SOCE activation in mammalian skeletal muscle fibers. J Physiol Sci 59:317-328

Boncompagni S, Rossi A, Micaroni M, Beznoussenko G, Polishchuk R, Dirksen R, Protasi F (2009) Mitochondria are linked to calcium stores in striated muscle by developmentally regulated tethering structures. Mol Biol Cell 20:1058-1067
Boncompagni S, Thomas M, Lopez J, Allen P, Yuan Q, Kranias E, Franzini-Armstrong C, Perez C (2013) Triadin/Junctin double null mouse reveals a differential role for Triadin and Junctin in anchoring CASQ to the jSR and regulating $\mathrm{Ca}(2+)$ homeostasis. PLoS ONE 7: e39962

Bottinelli R, Reggiani C (2000) Human skeletal muscle fibres: molecular and functional diversity. Prog Biophys Mol Biol 73:195-262

Brochet D, Yang D, Di Maio A, Lederer W, Franzini-Armstrong C, Cheng H (2005) Ca2+ blinks: rapid nanoscopic store calcium signaling. Proc Natl Acad Sci U S A 102:3099-3104

Brooke M, Kaiser K (1970) Three "myosin adenosine triphosphatase" systems: the nature of their $\mathrm{pH}$ lability and sulfhydryl dependence. J Histochem Cytochem 18:670-672

Brotto M, Nosek T (1996) Hydrogen peroxide disrupts $\mathrm{Ca}^{2+}$ release from the sarcoplasmic reticulum of rat skeletal muscle fibers. J Appl Physiol 81:731-737

Bruton J, Tavi P, Aydin J, Wasterblad H, Lanergren J (2003) Mitochondrial and myoplasmic $\left[\mathrm{Ca}^{2+}\right]$ in single fibers from Mouse limb muscles during repeated tetanic contraction. J Physiol 551: $179-190$

Bruton J, Place N, Yamada T, Silva J, Andrade F, Dahlstedt A, Zhang S, Katz A, Larsson N, Westerblad H (2008) Reactive oxygen species and fatigue-induced prolonged low-frequency force depression in skeletal muscle fibres of rats, mice and SOD2 overexpressing mice. J Physiol 586:175-184

Bruton J, Cheng A, Westerblad H (2012) Methods to detect Ca2+ in living cells. Adv Exp Med Biol 740:27-43

Buck E, Nguyen H, Pessah I, Allen P (1997) Dyspedic mouse skeletal muscle expresses major elements of the triadic junction but lacks detectable ryanodine receptor protein and function. J Biol Chem 272:7360-7367

Buntinas L, Gunter K, Sparagna G, Gunter T (2001) The rapid mode of calcium uptake into heart mitochondria (RaM): comparison to RaM in liver mitochondria. Biochim Biophys Acta 1504:248-261

Burke R, Levine D, Tsairis P, Zajac F (1973) Physiological types and histochemical profiles in motor units of the cat gastrocnemius. J Physiol 234:723-748

Calderón J (2013) Enzymatic dissociation of long muscles from mouse: a model for the study of fiber types in skeletal muscle. Iatreia 26:117126

Calderón JC, Bolaños P, Torres SH, Rodriguez-Arroyo G, Caputo C (2009) Different fibre populations distinguished by their calcium transient characteristics in enzymatically dissociated murine flexor digitorum brevis and soleus muscles. J Muscle Res Cell Motil 30: $125-137$

Calderón JC, Bolaños P, Caputo C (2010) Myosin heavy chain isoform composition and $\mathrm{Ca}^{2+}$ transients in fibres from enzymatically dissociated murine soleus and extensor digitorum longus muscles. J Physiol 588(1):267-279

Calderón JC, Bolaños P, Caputo C (2011) Kinetic changes in tetanic calcium transients in enzymatically dissociated muscle fibres under repetitive stimulation. J Physiol 589(21):5269-5283

Calderón J, Raigosa D, Giraldo M, Bolaños P, Caputo C (2013) Calibration of $\mathrm{Ca} 2+$ transients obtained with the fast $\mathrm{Ca} 2+$ and $\mathrm{Mg} 2+$ dye Magfluo-4. Biophys J 104(2-S1):293a. abstract,1502-Pos

Calderón-Vélez J, Figueroa-Gordon C (2009) El acoplamiento exitacióncontracción en el músculo esquelético: preguntas por responder a pesar de 50 años de studio. Biomedica 29:140-160

Caputo C (1983) Pharmacological investigations of excitation-contraction coupling. Chapter 14. In: Peachey L, Adrian R (eds) Handbook of physiology. American Physiological Society, Bethesda

Caputo C, Bolaños P (2008) Effect of mitochondria poisoning by FCCP on $\mathrm{Ca} 2+$ signaling in mouse skeletal muscle fibers. Pflugers Arch 455:733-743

Caputo C, Giménez M (1967) Effects of external Ca2+ deprivation on single muscle fibres. J Gen Physiol 50:2177-2195 
Caputo C, Edman K, Lou F, Sun Y (1994) Variation in myoplasmic Ca concentration during contraction and relaxation studied by the indicator fluo-3 in frog muscle fibres. J Physiol 478:137-148

Caputo C, Bolaños P, Escobar A (1999) Fast calcium removal during single twitches in amphibian skeletal muscle fibres. J Muscle Res Cell Motil 20:555-567

Caputo C, Bolaños P, González A (2004) Inactivation of Ca2+ transients in amphibian and mammalian muscle fibres. J Muscle Res Cell Motil 25:315-328

Carafoli E, Tiozzo R, Lugli G, Crovetti F, Kratzing C (1974) The release of calcium from heart mitochondria by sodium. J Mol Cell Cardiol 6:361-371

Carroll S, Klein M, Schneider M (1997) Decay of calcium transients after electrical stimulation in rat fast- and slow-twitch skeletal muscle fibres. J Physiol 501:573-588

Casarotto M, Cui Y, Karunasekara Y, Harvey P, Norris N, Borrad P et al (2006) Structural and functional characterization of interactions between the dihydropyridine receptor II-III loop and the ryanodine receptor. Clin Exp Pharmacol Physiol 33:1114-1117

Casas M, Figueroa R, Jorquera G, Escobar M, Molgó J, Jaimovich E (2010) IP(3)-dependent, post-tetanic calcium transients induced by electrostimulation of adult skeletal muscle fibers. J Gen Physiol 136: 455-467

Cheng H, Lederer W (2008) Calcium sparks. Physiol Rev 88:1491-1545

Cheng H, Lederer W, Cannell M (1993) Calcium sparks: elementary events underlying excitation-contraction coupling in heart muscle. Science 262:740-744

Cheung A, Dantzig J, Hollingworth S, Baylor S, Goldman Y, Mitchison T, Straight A (2002) A small-molecule inhibitor of skeletal muscle myosin II. Nat Cell Biol 4:83-89

Chin E, Allen D (1998) The contribution of pH-dependent mechanisms to fatigue at different intensities in mammalian single muscle fibres. J Physiol 512:831-840

Coronado R, Morrissette J, Sukhareva, Vaughan D (1994) Structure and function of ryanodine receptors. Am J Physiol 266:C1485-C1504

Craig R, Padrón R (2004) Molecular structure of the sarcomere. Chapter 7. In: Engel A, Franzini-Armstrong C (eds) Myology, 3rd edn. McGrawHill, New York, pp 129-166

Csordás G, Renken C, Várnai P, Walter L, Weaver D, Buttle K, Balla T, Mannella C, Hajnóczky G (2006) Structural and functional features and significance of the physical linkage between ER and mitochondria. J Cell Biol 174:915-921

Cully T, Launikonis B (2013) Store-operated Ca2+ entry is not required for store refilling in skeletal muscle. Clin Exp Pharmacol Physiol 40: 338-344

Dahlstedt AJ, Katz A, Westerblad H (2001) Role of myoplasmic phosphate in contractile function of skeletal muscle: studies on creatine kinase-deficient mice. J Physiol 533:379-388

Damiani E, Margreth A (1994) Characterization study of the ryanodine receptor and of calsequestrin isoforms of mammalian skeletal muscles in relation to fibre types. J Muscle Res Cell Motil 15:86-101

Darnley G, Duke A, Steele D, MacFarlane N (2001) Effects of reactive oxygen species on aspects of excitation-contraction coupling in chemically skinned rabbit diaphragm muscle fibres. Exp Physiol 86:161-168

Davies K, Quintanilha A, Brooks G, Packer L (1982) Free radicals and tissue damage produced by exercise. Biochem Biophys Res Commun 107:1198-1205

de Brito O, Scorrano L (2008) Mitofusin 2 tethers endoplasmic reticulum to mitochondria. Nature 456:605-610

De Stefani D, Raffaello A, Teardo E, Szabo I, Rizzuto R (2011) A fortykilodalton protein of the inner membrane is the mitochondrial calcium uniporter. Nature 476:336-340

Delay M, Garcia D, Sanchez J (1990) The effects of lyotropic anion on charge movement, calcium currents and calcium signals in frog skeletal muscle fibres. J Physiol 425:449-469
Delbono O, Stefani E (1993) Calcium transients in single mammalian skeletal muscle fibres. J Physiol 463:689-707

DiFranco M, Neco P, Capote J, Meera P, Vergara J (2006) Quantitative evaluation of mammalian skeletal muscle as a heterologous protein expression system. Protein Expr Purif 47:281-288

DiFranco M, Tran P, Quiñonez M, Vergara J (2011) Functional expression of transgenic 1sDHPR channels in adult mammalian skeletal muscle fibres. J Physiol 589:1421-1442

Dirksen R (2009a) Checking your SOCCs and feet: the molecular mechanisms of $\mathrm{Ca} 2+$ entry in skeletal muscle. J Physiol 587: $3139-3147$

Dirksen R (2009b) Sarcoplasmic reticulum-mitochondrial through-space coupling in skeletal muscle. Appl Physiol Nutr Metab 34:389-395

Doyle D, Morais Cabral J, Pfuetzner R, Kuo A, Gulbis J, Cohen S et al (1998) The structure of potassium channel: molecular basis of $\mathrm{K}^{+}$ conduction and selectivity. Science 280:69-77

Drago I, De Stefani D, Rizzuto R, Pozzan T (2012) Mitochondrial Ca2+ uptake contributes to buffering cytoplasmic $\mathrm{Ca} 2+$ peaks in cardiomyocytes. Proc Natl Acad Sci U S A 109:12986-12991

Dubowitz V, Pearse A (1960) A comparative histochemical study of oxidative enzyme and phophorylase activity in skeletal muscle. Histochemie 2:105-117

Ducret T, Vandebrouck C, Cao M, Lebacq J, Gailly P (2006) Functional role of store-operated and stretch-activated channels in murine adult skeletal muscle fibres. J Physiol 575:913-924

Duke A, Steele D (2000) Characteristics of phosphate-induced $\mathrm{Ca}(2+)$ efflux from the SR in mechanically skinned rat skeletal muscle fibers. Am J Physiol Cell Physiol 278:C126-C135

Dulhunty A, Banyard M, Medveczky C (1987) Distribution of calcium ATPase in the sarcoplasmic reticulum of fast- and slow-twitch muscles determined with monoclonal antibodies. J Membr Biol 99:79-92

Dutka T, Cole L, Lamb G (2005) Calcium phosphate precipitation in the sarcoplasmic reticulum reduces action potential-mediated $\mathrm{Ca}^{2+}$ release in mammalian skeletal muscle. Am J Physiol 289:C1502-C1512

Ebashi S (1974) Regulatory mechanism of muscle contraction with special reference to the Ca-troponin-tropomyosin system. Essays Biochem 10:1-36

Ebashi S, Endo M, Ohtsuki I (1969) Control of muscle contraction. Q Rev Biophys 2:351-384

Edman K (2005) Contratile properties of mouse single muscle fibers, a comparison with amphibian muscle fibers. J Exp Biol 208:19051913

Edwards J, Murphy R, Cully T, von Wegner F, Friedrich O, Launikonis B (2010) Ultra-rapid activation and deactivation of store-operated $\mathrm{Ca}(2+)$ entry in skeletal muscle. Cell Calcium 47: $458-467$

Edwards J, Cully T, Shannon T, Stephenson D, Launikonis B (2012) Longitudinal and transversal propagation of excitation along the tubular system of rat fast-twitch muscle fibres studied by high speed confocal microscopy. J Physiol 590:475-492

Eisenberg B (1983) Quantitative ultrastructure of mammalian skeletal muscle. In: Peachey LD (ed) Handbook of Physiology Skeletal Muscle. American Physiological Society, Bethesda, p 95

Eisner V, Csordás G, Hajnóczky G (2013) Interactions between sarcoendoplasmic reticulum and mitochondria in cardiac and skeletal muscle - pivotal roles in $\mathrm{Ca} 2+$ and reactive oxygen species signaling. J Cell Sci 126:2965-2978

el-Hayek R, Antoniu B, Wang J, Hamilton SL, Ikemoto N (1995) Identification of calcium release-triggering and blocking regions of the II-III loop of the skeletal muscle dihydropyridine receptor. J Biol Chem 270:22116-22118

Endo M (1975) Mechanism of action of caffeine on the sarcoplasmic reticulum of skeletal muscle. Proc Jpn Acad 51:479-484

Endo M (2009) Calcium-induced calcium release in skeletal muscle. Physiol Rev 89:1153-1176 
Endo M, Tanaka M, Ogawa Y (1970) Calcium induced release of calcium from the sarcoplasmic reticulum of skinned skeletal muscle fibres. Nature 228:34-36

Escobar A, Monck J, Fernandez J, Vergara J (1994) Localization of the site of $\mathrm{Ca}^{2+}$ release at the level of a single sarcomere in skeletal muscle fibres. Nature 367:739-741

Eusebi F, Miledi R, Takahashi T (1980) Calcium transients in mammalian muscles. Nature 284:560-561

Fabiato A (1984) Dependence of the $\mathrm{Ca}^{2+}$-induced release from the sarcoplasmic reticulum of skinned skeletal muscle fibres from the frog semitendinosus on the rate of change of free $\mathrm{Ca}^{2+}$ concentration at the outer surface of the sarcoplasmic reticulum. J Physiol 353:56P

Farkas D, Wei M, Febbroriello P, Carson J, Loew L (1989) Simultaneous imaging of cell and mitochondrial membrane potentials. Biophys J 56:1053-1069

Felder E, Franzini-Armstrong C (2002) Type 3 ryanodine receptors of skeletal muscle are segregated in a parajunctional position. Proc Natl Acad Sci U S A 99:1695-1700

Ferguson D, Franzini-Armstrong C (1988) The $\mathrm{Ca}^{2+}$ ATPase content of slow and fast twitch fibers of guinea pig. Muscle Nerve 11:561-570

Feske S, Gwack Y, Prakriya M, Srikanth S, Puppel S, Tanasa B, Hogan P, Lewis R, Daly M, Rao A (2006) A mutation in Orail causes immune deficiency by abrogating CRAC channel function. Nature 441:179-185

Fieni F, Lee SB, Jan YN, Kirichok Y (2012) Activity of the mitochondrial calcium uniporter varies greatly between tissues. Nat Commun 3:1317

Figueroa L, Shkryl VM, Zhou J, Manno C, Momotake A, Brum G, Blatter LA, Ellis-Davies GC, Ríos E (2012) Synthetic localized calcium transients directly probe signalling mechanisms in skeletal muscle. J Physiol 590:1389-1411

Fill M, Copello J (2002) Ryanodine receptor calcium release channels. Physiol Rev 82:893-922

Fitts R (1994) Cellular mechanisms of muscle fatigue. Physiol Rev 74:49-94

Foulks J, Miller J, Perry F (1973) Repolarization-induced reactivation ofcontracture tension in frog skeletal muscle. Can J Physiol Pharmacol 51:324-334

Fourest-Lieuvin A, Rendu J, Osseni A, Pernet-Gallay K, Rossi D, Oddoux S, Brocard J, Sorrentino V, Marty I, Fauré J (2012) Role of triadin in the organization of reticulum membrane at the muscle triad. J Cell Sci 125:3443-3453

Franke W, Kartenbeck J (1971) Outer mitochondrial membrane continuous with endoplasmic reticulum. Protoplasma 73:35-41

Franzini-Armstrong C (1999) The sarcoplasmic reticulum and the control of muscle contraction. FASEB J 13:S266-S270

Franzini-Armstrong C (2007) ER-mitochondria communication. How privileged? Physiology (Bethesda) 22:261-268

Franzini-Armstrong C, Boncompagni S (2011) The evolution of the mitochondria-to-calcium release units relationship in vertebrate skeletal muscles. J Biomed Biotechnol 2011:830573

Franzini-Armstrong C, Jorgensen A (1994) Structure and development of e-c coupling units in skeletal muscle. Annu Rev Physiol 56:509-534

Franzini-Armstrong C, Porter K (1964) Sarcolemmal invaginations constituting the T system in fish muscle fibres. J Cell Biol 22:675-696

Franzini-Armstrong C, Ferguson D, Champ C (1988) Discrimination between fast- and slow-twitch fibres of guinea pig skeletal muscle using the relative surface density of junctional transverse tubule membrane. J Muscle Res Cell Motil 9:403-414

Fraysse B, Rouaud T, Millour M, Fontaine-Pérus J, Gardahaut M, Levitsky D (2001) Expression of the $\mathrm{Na}^{+} / \mathrm{Ca}^{2+}$ exchanger in skeletal muscle. Am J Physiol 280:C146-C154

Fryer M, Stephenson G (1996) Total and sarcoplasmic reticulum calcium contents of skinned fibres from rat skeletal muscle. J Physiol 493: $357-370$

Fryer M, Owen V, Lamb G, Stephenson G (1995) Effects of creatine phosphate and $\mathrm{Pi}$ on $\mathrm{Ca}$ movements and tension development in rat skinned skeletal muscle fibres. J Physiol 482:123-140
Füchtbauer E, Rowlerson A, Gotz K, Friedrich G, Mabuchi K, Gergely J, Jockusch H (1991) Direct correlation of parvalbumin levels with myosin isoforms and succinate dehydrogenase activity on frozen sections of rodent muscle. J Histochem Cytochem 39:355-361

Gauthier G, Padykula H (1966) Cytological studies of fiber types in skeletal muscle. J Cell Biol 28:333-354

Gillis J (1997) Inhibition of mitochondrial calcium uptake slows down relaxation in mitochondria-rich skeletal muscles. J Muscle Res Cell Motil 18:473-483

Gillis J, Thomason D, Lefévre J, Kretsinger R (1982) Parvalbumins and muscle relaxation: a computer simulation study. J Muscle Res Cell Motil 3:377-398

Giorgio V, von Stockum S, Antoniel M, Fabbro A, Fogolari F, Forte M, Glick G, Petronilli V, Zoratti M, Szabo I, Lippe G, Bernardi P (2013) Dimers of mitochondrial ATP synthase form the permeability transition pore. Proc Natl Acad Sci U S A 110:5887-5892

Glitsch M, Bakowski D, Parekh A (2002) Store-operated Ca2+ entry depends on mitochondrial Ca2+ uptake. EMBO J 21:6744-6754

Gollnick P, Korge P, Karpakka J, Saltin B (1991) Elongation of skeletal muscle relaxation during exercise is linked to reduced calcium uptake by the sarcoplasmic reticulum in man. Acta Physiol Scand 142:135-136

Gomolla M, Gottschalk G, Lüttgau H (1983) Perchlorate-induced alterations in electrical and mechanical parameters of frog skeletal muscle fibres. J Physiol 343:197-214

Gonzalez Narvaez A, Castillo A (2007) Ca2+ store determines gating of store operated calcium entry in mammalian skeletal muscle. J Muscle Res Cell Motil 28:105-113

González-Serratos H (1971) Inward spread of activation in vertebrate muscle fibres. J Physiol 212:777-799

Goonasekera S, Beard N, Groom L, Kimura T, Lyfenko A, Rosenfeld A, Marty I, Dulhunty A, Dirksen R (2007) Triadin binding to the Cterminal luminal loop of the ryanodine receptor is important for skeletal muscle excitation-contraction coupling. J Gen Physiol 130:365-378

Grabowski W, Lobsiger E, Luttgau H (1972) The effect of repetitive stimulation at low frequencies upon the electrical and mechanical activity of single muscle fibres. Pflugers Arch 334:222-239

Green H (1998) Cation pumps in skeletal muscle: potential role in muscle fatigue. Acta Physiol Scand 162:201-213

Grynkiewicz G, Poenie M, Tsien R (1985) A New Generation of $\mathrm{Ca}^{2+}$ Indicators with Greatly Improved Fluorescence Properties. J Biol Chem 260:3440-3450

Gunter T, Pfeiffer D (1990) Mechanisms by which mitochondria transport calcium. Am J Physiol 258:C755-C786

Gunter T, Gunter K, Sheu S, Gavin C (1994) Mitochondrial calcium transport: physiological and pathological relevance. Am J Physiol 267:C313-C339

Gustafsson M (2000) Surpassing the lateral resolution limit by a factor of two using structured illumination microscopy. J Microsc 198:82-87

Hasselbach W (1964) Relaxing factor and the relaxation of muscle. Prog Biophys Mol Biol 14:167-222

Hasselbach W (1998) The $\mathrm{Ca}^{2+}$-ATPase of the sarcoplasmic reticulum in skeletal and cardiac muscle. Ann NY Acad Sci 853:1-8

Hasselbach W, Makinose M (1961) The calcium pump of the "relaxing granules" of muscle and its dependence on ATP splitting. Biochem Z 333:518-528

Hasselbach W, Suko J, Stromer M, The R (1975) Mechanism of calcium transport in sarcoplasmic reticulum. Ann NY Acad Sci 264: 335-349

He ZH, Bottinelli R, Pellegrino MA, Ferenczi MA, Reggiani C (2000) ATP consumption and efficiency of human single muscle fibers with different myosin isoform composition. Biophys $\mathrm{J} 79$ : 945-961

Heilbrunn L, Wiercinsky F (1947) The action of various cations on muscle protoplasm. J Cell Comp Physiol 29:15-32 
Heizmann C, Berchtold M, Rowlerson A (1982) Correlation of parvalbumin concentration with relaxation speed in mammalian muscle. Proc Natl Acad Sci U S A 79:7243-7247

Hell SW, Wichmann J (1994) Breaking the diffraction resolution limit by stimulated emission: stimulated-emission-depletion fluorescence microscopy. Opt Lett 19:780-782

Hernández-Ochoa E, Schneider M (2012) Voltage clamp methods for the study of membrane currents and $\mathrm{SR} \mathrm{Ca}^{2+}$ release in adult skeletal muscle fibres. Prog Biophys Mol Biol 108:98-118

Hidalgo $\mathrm{C}$ (2005) Cross talk between $\mathrm{Ca}^{2+}$ and redox signaling cascades in muscle and neurons through the combined activation of ryanodine receptors $/ \mathrm{Ca}^{2+}$ release channels. Phil Trans R Soc B 360:2237-2246

Hill A (1949) The abrupt transition from rest to activity in muscle. Proc R Soc B 136:399-420

Hill A, Kupalov P (1929) Anaerobic and aerobic activity in isolated muscle. Proc R Soc London B 105:313-322

Hille B, Campbell T (1976) An improved Vaseline gap voltage clamp for skeletal muscle fibers. J Gen Physiol 67:265-293

Hodgkin A, Horowicz P (1959) The influence of potassium and chloride ions on the membrane potential of single muscle fibres. J Physiol 148:127-160

Hodgkin A, Horowicz P (1960) The effect of nitrate and other anions on the mechanical response of single muscle fibers. J Physiol 153:404-412

Hodgkin A, Huxley A (1952) A quantitative description of membrane current and its application to conduction and excitation in nerve. J Physiol 117:500-544

Hollingworth S, Marshall M (1981) A comparative study of charge movement in rat and frog skeletal muscle fibres. J Physiol 321: 583-602

Hollingworth S, Gee K, Baylor S (2009) Low-affinity Ca2+ indicators compared in measurements of skeletal muscle $\mathrm{Ca} 2+$ transients. Biophys J 97:1864-1872

Hollingworth S, Kim M, Baylor S (2012) Measurement and simulation of myoplasmic calcium transients in mouse slow-twitch muscle fibres. J Physiol 590:575-594

Horowicz P (1961) Influence of ions on the membrane potential of muscle fibres. In: Shanes A (ed) Biophysics of physiological and pharmacological actions. Washington, American Association for the Advancement of Science, pp 217-234

Hoth M, Penner R (1992) Depletion of intracellular calcium stores activates a calcium current in mast cells. Nature 355:353-356

Hoth M, Button D, Lewis R (2000) Mitochondrial control of calciumchannel gating: a mechanism for sustained signaling and transcriptional activation in T lymphocytes. Proc Natl Acad Sci U S A 97: 10607-10612

Hudecova S, Vadaszova A, Soukup T, Krizanova O (2004) Effect of thyroid hormones on the gene expression of calcium transport systems in rat muscles. Life Sci 75:923-931

Hunter D, Haworth R (1979) The Ca2+-induced membrane transition in mitochondria. III. Transitional $\mathrm{Ca} 2+$ release. Arch Biochem Biophys 195:468-477

Huxley H (1964) Evidence for continuity between the central elements of the triads and extracellular space in frog sartorius muscle. Nature 202:1067

Huxley H (1969) The mechanism of muscular contraction. Science 164: 1356-1366

Isaeva E, Shirokova N (2003) Metabolic regulation of $\mathrm{Ca}^{2+}$ release in permeabilized mammalian skeletal muscle fibres. J Physiol 547: 453-462

Isaeva E, Shkryl V, Shirokova N (2005) Mitochondrial redox state and $\mathrm{Ca} 2+$ sparks in permeabilized mammalian skeletal muscle. J Physiol 565:855-872

James P, Inui M, Tada M, Chiesi M, Carafoli E (1989) Nature and site of phospholamban regulation of the $\mathrm{Ca} 2+$ pump of sarcoplasmic reticulum. Nature 342:90-92
Jayasinghe I, Baddeley D, Kong C, Wehrens X, Cannell M, Soeller C (2012) Nanoscale organization of junctophilin-2 and ryanodine receptors within peripheral couplings of rat ventricular cardiomyocytes. Biophys J 102(5):L19-L21

Jiang Y, Lee A, Chen J, Cadene M, Chalt B, MacKinnon R (2002) The open pore conformation of potassium channels. Nature 417:523-526

Jiang D, Zhao L, Clapham D (2009) Genome-wide RNAi screen identifies Letm1 as a mitochondrial $\mathrm{Ca} 2+/ \mathrm{H}+$ antiporter. Science 326: 144-147

Jorgensen A, Jones L (1986) Localization of phospholamban in slow but not fast canine skeletal muscle fibers. J Biol Chem 261:3775-3781

Jung D, Baysal K, Brierley G (1995) The sodium-calcium antiport of heart mitochondria is not electroneutral. J Biol Chem 270:672-678

Jung D, Mo S, Kim D (2006) Calumenin, a multiple EF-hands Ca2+binding protein, interacts with ryanodine receptor- 1 in rabbit skeletal sarcoplasmic reticulum. Biochem Biophys Res Commun 34:34-42

Kahn A, Sandow A (1950) The potentiation of muscular contraction by the nitrate-ion. Science 112:647-649

Kanter M, Nolte L, Holloszy J (1993) Effects of an antioxidant vitamin mixture on lipid peroxidation at rest and postexercise. J Appl Physiol 74:965-969

Kao C, Stanfield P (1968) Action of some ions on the electrical properties and mechanical threshold of frog twitch muscle. J Physiol 198:291309

Kao J, Li G, Auston D (2010) Practical aspects of measuring intracellular calcium signals with fluorescent indicators. Methods Cell Biol 99: $113-152$

Katerinopoulos H, Foukaraki E (2002) Polycarboxylate fluorescent indicators as ion concentration probes in biological systems. Curr Med Chem 9:275-306

Kent-Braun J (1999) Central and peripheral contributions to muscle fatigue in humans during sustained maximal effort. Eur J Appl Physiol 80:57-63

Kent-Braun J, Miller R, Weiner M (1993) Phases of metabolism during progressive exercise to fatigue in human skeletal muscle. J Appl Physiol 75:573-580

Kinnally K, Campo M, Tedeschi H (1989) Mitochondrial channel activity studied by patch-clamping mitoplasts. J Bioenerg Biomembr 21: 497-506

Kirichok Y, Krapivinsky G, Clapham D (2004) The mitochondrial calcium uniporter is a highly selective ion channel. Nature 427:360-364

Klar T, Jakobs S, Dyba M, Egner A, Hell S (2000) Fluorescence microscopy with diffraction resolution barrier broken by stimulated emission. Proc Natl Acad Sci U S A 97:8206-8210

Klein M, Simon B, Szucs G, Schneider M (1988) Simultaneous recording of calcium transients in skeletal muscle using high and low-affinity calcium indicators. Biophys J 53:971-988

Knuth S, Dave H, Peters J, Fitts R (2006) Low cell pH depresses peak power in rat skeletal muscle fibres at both $30{ }^{\circ} \mathrm{C}$ and $15{ }^{\circ} \mathrm{C}$ : implications for muscle fatigue. J Physiol 575:887-899

Konishi M, Hollingworth S, Harkins A, Baylor S (1991) Myoplasmic calcium transients in intact frog skeletal muscle fibers monitored with the fluorescent indicator furaptra. J Gen Physiol 97:271-301

Kornmann B, Currie E, Collins SR, Schuldiner M, Nunnari J, Weissman J, Walter P (2009) An ER-mitochondria tethering complex revealed by a synthetic biology screen. Science 325:477-481

Kovács L, Schneider M (1978) Contractile activation by voltage clamp depolarization of cut skeletal muscle fibres. J Physiol 277:483-506

Kovács L, Ríos E, Schneider M (1983) Measurement and modification of free calcium transients in frog skeletal muscle fibres by a metallochromic indicator dye. J Physiol 343:161-196

Kurebayashi N, Ogawa Y (2001) Depletion of Ca2+ in the sarcoplasmic reticulum stimulates $\mathrm{Ca} 2+$ entry into mouse skeletal muscle fibres. J Physiol 533:185-199

Kuznetsov A, Troppmair J, Sucher R, Hermann M, Saks V, Margreiter R (2006) Mitochondrial subpopulations and heterogeneity revealed by 
confocal imaging: possible physiological role? Biochim Biophys Acta 1757:686-691

Lacampagne A, Lederer W, Schneider M, Klein M (1996) Repriming and activation alter the frequency of stereotyped discrete $\mathrm{Ca} 2+$ release events in frog skeletal muscle. J Physiol 497:581-588

Lai F, Erickson H, Rousseau E, Liu Q, Meissner G (1988) Purification and reconstitution of the calcium release channel from skeletal muscle. Nature 331:315-319

Lamb G (2002) Excitation-contraction coupling and fatigue mechanisms in skeletal muscle: studies with mecanically skinned fibres. J Muscle Res Cell Motil 23:81-91

Lamb G, Stephenson D (1994) Effects of intracellular $\mathrm{pH}$ and $\left[\mathrm{Mg}^{2+}\right]$ on excitation-contraction coupling in skeletal muscle fibres of the rat. J Physiol 478:331-339

Lamb G, Walsh T (1987) Calcium currents, charge movement and dihydropyridine binding in fast- and slow-twitch muscles of rat and rabbit. J Physiol 393:595-617

Lamb G, Junankar P, Stephenson D (1995) Raised intracellular $\mathrm{Ca}^{2+}$ abolishes excitation-contraction coupling in skeletal muscle fibres of rat and toad. J Physiol 489:349-362

Lännergren J, Westerblad H (1987) The temperature dependence of isometric contractions of single, intact fibres dissected from a mouse foot muscle. J Physiol 390:285-293

Lännergren J, Westerblad H, Bruton J (2001) Changes in mitochondrial $\mathrm{Ca}^{2+}$ detected with Rhod-2 in single frog and mouse skeletal muscle fibres during and after repeated tetanic contractions. J Muscle Res Cell Motil 22:265-275

Launikonis B, Ríos E (2007) Store-operated Ca2+ entry during intracellular $\mathrm{Ca} 2+$ release in mammalian skeletal muscle. J Physiol 583:81-97

Launikonis BS, Zhou J, Royer L, Shannon T, Brum G, Ríos E (2005) Confocal imaging of $\left[\mathrm{Ca}^{2+}\right]$ in cellular organelles by SEER, shifted excitation and emission ratioing of fluorescence. J Physiol 567:523-543

Leberer E, Pette D (1986) Immunochemical quantification of sarcoplasmic reticulum Ca-ATPase, of calsequestrin and of parvalbumin in rabbit skeletal muscles. Eur J Biochem 156:489-496

Leong P, MacLennan D (1998) A 37-amino acid sequence in the skeletal muscle ryanodine receptor interacts with the cytoplasmic loop between domains II and III in the skeletal muscle dihydropyridine receptor. J Biol Chem 273:7791-7794

Leppik J, Aughey R, Medved I, Fairweather I, Carey M, McKenna M (2004) Prolongued exercise to fatigue in humans impairs skeletal muscle Na-K ATPase activity, sarcoplasmic reticulum Ca release and Ca uptake. J Appl Physiol 97:1414-1423

Lewis J, Tata J (1973) A rapidly sedimenting fraction of rat liver endoplasmic reticulum. J Cell Sci 13:447-459

Lindinger M, Heigenhauser G (1991) The roles of ion fluxes in skeletal muscle fatigue. Can J Physiol Pharmacol 69:246-253

Liou J, Kim M, Heo W, Jones J, Myers J, Ferrell J Jr, Meyer T (2005) STIM is a $\mathrm{Ca} 2+$ sensor essential for $\mathrm{Ca} 2+$-store-depletion-triggered $\mathrm{Ca} 2+$ influx. Curr Biol 15:1235-1241

Lipp P, Niggli E (1996) Submicroscopic calcium signals as fundamental events of excitation-contraction coupling in guinea-pig cardiac myocytes. J Physiol 492:31-38

Ludtke S, Serysheva I, Hamilton S, Chiu W (2005) The pore structure of the closed RyR1 channel. Structure 13:1203-1211

Luff A, Atwood H (1972) Membrane properties and contraction of single muscle fibers in the mouse. Am J Physiol 222:1435-1440

Luik R, Wu M, Buchanan J, Lewis R (2006) The elementary unit of storeoperated $\mathrm{Ca} 2+$ entry: local activation of CRAC channels by STIM1 at ER-plasma membrane junctions. J Cell Biol 174:815-825

Luttgau H (1965) The effect of metabolic inhibitors on the fatigue of the action potential in single muscle fibres. J Physiol 178:45-67

Lüttgau H, Oetliker H (1968) The action of caffeine on the activation of the contractile mechanism in striated muscle fibres. J Physiol 194: $51-74$
Ma J, Pan Z (2003) Junctional membrane structure and store operated calcium entry in muscle cells. Front Biosci 8:d242-d255

MacLennan D, Brandl C, Korczak B, Green N (1985) Amino-acid sequence of a $\mathrm{Ca}^{2+}+\mathrm{Mg}^{2+}$-dependent ATPase from rabbit muscle sarcoplasmic reticulum, deduced from its complementary DNA sequence. Nature 316:696-700

Mannella C, Colombini M, Frank J (1983) Structural and functional evidence for multiple channel complexes in the outer membrane of Neurospora crassa mitochondria. Proc Natl Acad Sci U S A 80: 2243-2247

Mannella C, Buttle K, Rath B, Marko M (1998) Electron microscopic tomography of rat-liver mitochondria and their interaction with the endoplasmic reticulum. Biofactors 8:225-228

Manno C, Figueroa L, Fitts R, Ríos E (2013) Confocal imaging of transmembrane voltage by SEER of di-8-ANEPPS. J Gen Physiol 141(3):371-387

Martonosi A, Pikula S (2003) The structure of the $\mathrm{Ca}^{2+}$-ATPase of sarcoplasmic reticulum. Acta Biochim Pol 50:337-365

McCully K, Clark B, Kent J, Wilson J, Chance B (1991) Biochemical adaptations to training: implications for resisting muscle fatigue. Can J Physiol Pharmacol 69:274-278

McLaughlin S, Bruder A, Chen S, Moser C (1975) Chaotropic anions and the surface potential of bilayer membranes. Biochim Biophys Acta 394:304-313

Meier P, Spycher M, Meyer U (1981) Isolation and characterization of rough endoplasmic reticulum associated with mitochondria from normal rat liver. Biochim Biophys Acta 646:283-297

Meissner G (1984) Adenine nucleotide stimulation of $\mathrm{Ca}^{2+}$-induced $\mathrm{Ca}^{2+}$ release in sarcoplasmic reticulum. J Biol Chem 259: $2365-2374$

Michaelson L, Shi G, Ward C, Rodney G (2010) Mitochondrial redox potential during contraction in single intact muscle fibers. Muscle Nerve 42:522-529

Miledi R, Parker I, Schalow G (1977) Calcium transients in frog slow muscle fibres. Nature 268:750-752

Minta A, Kao J, Tsien R (1989) Fluorescent indicators for cytosolic calcium based on rhodamine and fluorescein chromophores. J Biol Chem 264:8171-8178

Mitchell P, Moyle J (1967) Chemiosmotic hypothesis of oxidative phosphorylation. Nature 213:137-139

Moopanar T, Allen D (2005) Reactive oxygen species reduce myofibrillar $\mathrm{Ca}^{2+}$ sensitivity in fatiguing mouse skeletal muscle at $37^{\circ} \mathrm{C}$. $\mathrm{J}$ Physiol 564:189-199

Moopanar T, Allen D (2006) The activity-induced reduction of myofibrillar $\mathrm{Ca}^{2+}$ sensitivity in mouse skeletal muscle is reversed by dithiothreitol. J Physiol 571:191-200

Moore R, Nguyen H, Galceran J, Pessah I, Allen P (1998) A transgenic myogenic cell line lacking ryanodine receptor protein for homologous expression studies: reconstitution of $\mathrm{Ry}_{1} \mathrm{R}$ protein and function. J Cell Biol 140:843-851

Morre D, Merritt W, Lembi C (1971) Connections between mitochondria and endoplasmic reticulum in rat liver and onion stem. Protoplasma $73: 43-49$

Mosca B, Delbono O, Messi M, Bergamelli L, Wang Z, Vukcevic M, Lopez R, Treves S, Nishi M, Takeshima H, Paolini C, Martini M, Rispoli G, Protasi F, Zorzato F (2013) Enhanced dihydropyridine receptor calcium channel activity restores muscle strength in JP45/CASQ1 double knockout mice. Nat Commun 4: 1541

Moussavi R, Carson P, Boska M, Weiner M, Miller R (1989) Nonmetabolic fatigue in exercising human muscle. Neurology 39: $1222-1226$

Muik M, Fahrner M, Derler I, Schindl R, Bergsmann J, Frischauf I, Groschner K, Romanin C (2009) A Cytosolic Homomerization and a Modulatory Domain within STIM1 C Terminus Determine Coupling to ORAI1 Channels. J Biol Chem 284:8421-8426 
Naghdi S, Waldeck-Weiermair M, Fertschai I, Poteser M, Graier W, Malli $\mathrm{R}$ (2010) Mitochondrial Ca2+ uptake and not mitochondrial motility is required for STIM1-Orai1-dependent store-operated Ca2+ entry. J Cell Sci 123:2553-2564

Nakai J, Dirksen R, Nguyen H, Pessah I, Beam K, Allen P (1996) Enhanced dihydropyridine receptor channel activity in the presence of ryanodine receptor. Nature 380:72-75

Nassar-Gentina V, Passonneau J, Vergara J, Rapoport S (1978) Metabolic correlates of fatigue and recovery from fatigue in single frog muscle fibers. J Gen Physiol 72:593-606

Natori R (1954) The property and contraction process of isolated myofibrils. Jikeikai Med J 1:119-126

Niedergerke R (1955) Local muscular shortening by intracellularly applied calcium. J Physiol 128:12P-13P

Oba T, Kurono C, Nakajima R, Takaishi T, Ishida K, Fuller G, Klomkleaw W, Yamaguchi M (2002) $\mathrm{H}_{2} \mathrm{O}_{2}$ activates ryanodine receptor but has little effect on recovery of release $\mathrm{Ca}^{2+}$ content after fatigue. J Appl Physiol 93:1999-2008

O'Brien J, Valdivia H, Block B (1995) Physiological differences between the alpha and beta ryanodine receptors of fish skeletal muscle. Biophys J 68:471-482

Odermatt A, Becker S, Khanna V, Kurzydlowski K, Leisner E, Pette D, MacLennan D (1998) Sarcolipin regulates the activity of SERCA1, the fast-twitch skeletal muscle sarcoplasmic reticulum $\mathrm{Ca}^{2+}$-ATPase. J Biol Chem 273:12360-12369

Ogata T, Yamasaki Y (1985) Scanning electron-microscopic studies on the three-dimensional structure of sarcoplasmic reticulum in the mammalian red, white and intermediate muscle fibers. Cell Tissue Res 242:461-467

Pacher P, Thomas A, Hajnoczky G (2002) $\mathrm{Ca}^{2+}$ marks: miniature calcium signals in single mitochondria driven by ryanodine receptors. Proc Natl Acad Sci U S A 99:2380-2385

Pal R, Li S, Thakur P, Rodney G (2013) Real-time imaging of NADPH oxidase activity in living cell by using novel bio-sensor. Biophys $\mathrm{J}$ 104(2-S1):530a. abstract,2722-Pos

Palmer A, Tsien R (2006) Measuring calcium signaling using genetically targetable fluorescent indicators. Nat Protoc 1: 1057-1065

Pan Z, Yang D, Nagaraj RY, Nosek TA, Nishi M, Takeshima H, Cheng H, Ma J (2002) Dysfunction of store-operated calcium channel in muscle cells lacking mg29. Nat Cell Biol 4:379383

Paolini C, Fessenden J, Pessah I, Franzini-Armstrong C (2004) Evidence for conformational coupling between two calcium channels. Proc Natl Acad Sci U S A 101:12748-12752

Paolini C, Quarta M, Nori A, Boncompagni S, Canato M, Volpe P, Allen PD, Reggiani C, Protasi F (2007) Reorganized stores and impaired calcium handling in skeletal muscle of mice lacking calsequestrin-1. J Physiol 583:767-784

Papadopoulus S, Leuranguer V, Bannister R, Beam K (2004) Mapping sites of potential proximity between the DHPR and RyR1 in muscle using a cyan fluorescent protein-yellow fluorescent protein tandem as a fluorescent resonance energy transfer probe. J Biol Chem 279: 44046-44056

Parekh A (2003) Store-operated Ca2+ entry: dynamic interplay between endoplasmic reticulum, mitochondria and plasma membrane. J Physiol 547:333-348

Parekh A, Penner R (1997) Store depletion and calcium influx. Physiol Rev 77:901-930

Parekh A, Putney J Jr (2005) Store-operated calcium channels. Physiol Rev 85:757-810

Peachey L (1965) The sarcoplasmic reticulum and transverse tubules of the frog's Sartorius. J Cell Biol 25:209-231

Pedersen T, Nielsen O, Lamb G, Stephenson D (2004) Intracellular acidosis enhances the excitability of working muscle. Science 305 : 1144-1147
Perez C, Thomas M, Franzini-Armstrong C (2013) Carboxyl-terminal domain of DHPR $\beta 1 \mathrm{~A}$ is essential for DHPR tetrad formation. Biophys J 104(2-S1):104a. abstract,542-Pos

Periasamy M, Kalyanasundaram A (2007) Serca pump isoforms: their role in calcium transport and disease. Muscle Nerve 35:430-442

Petrofsky J, Lind A (1979) Isometric endurance in fast and slow muscles in the cat. Am J Physiol 236:C185-C191

Petronilli V, Szabo I, Zoratti M (1989) The inner mitochondrial membrane contains ion-conducting channels similar to those found in bacteria. FEBS Lett 259:137-143

Picard M, Hepple R, Burelle Y (2012) Mitochondrial functional specialization in glycolytic and oxidative muscle fibers: tailoring the organelle for optimal function. Am J Physiol Cell Physiol 302:C629C641

Place N, Yamada T, Bruton JD, Westerblad H (2008) Interpolated twitches in fatiguing single mouse muscle fibres: implications for the assessment of central fatigue. J Physiol 586:2799-2805

Place N, Yamada T, Zhang S, Westerblad H, Bruton J (2009) High temperature does not alter fatigability in intact mouse skeletal muscle fibres. J Physiol 587:4717-4724

Place N, Yamada T, Bruton J, Westerblad H (2010) Muscle fatigue: from observations in humans to underlying mechanisms studied in intact single muscle fibres. Eur J Appl Physiol 110:1-15

Porter K, Palade G (1957) Studies on the endoplasmic reticulum. III. Its form and distribution in striated muscle cells. J Biophys Biochem Cytol 3(2):269-300

Posterino G, Lamb G (2003) Effect of sarcoplasmic reticulum $\mathrm{Ca}^{2+}$ content on action-potential induced $\mathrm{Ca} 2+$ release in rat skeletal muscle fibres. J Physiol 551:219-237

Pouvreau S, Collet C, Allard B, Jacquemond V (2007a) Whole-cell voltage clamp on skeletal muscle fibers with silicone-clamp technique. Methods Mol Biol 403:185-194

Pouvreau S, Royer L, Yi J, Brum G, Meissner G, Ríos E, Zhou J (2007b) $\mathrm{Ca}(2+)$ sparks operated by membrane depolarization require isoform 3 ryanodine receptor channels in skeletal muscle. Proc Natl Acad Sci U S A 104:5235-5240

Prakriya M, Feske S, Gwack Y, Srikanth S, Rao A, Hogan P (2006) Orail is an essential pore subunit of the CRAC channel. Nature 443:230-233

Prosser B, Wright N, Hernandez-Ochoa E, Varney K, Liu Y, Olojo R, Zimmer D, Weber D, Schneider M (2008) S100A1 binds to the calmodulin binding site of ryanodine receptor and modulates skeletal muscle coupling. J Biol Chem 283:5046-5057

Prosser B, Hernández-Ochoa E, Lovering R, Andronache Z, Zimmer D, Melzer W, Schneider M (2010) S100A1 promotes action potentialinitiated calcium release flux and force production in skeletal muscle. Am J Physiol Cell Physiol 299:C891-C902

Protasi F, Paolini C, Nakai J, Beam K, Franzini-Armstrong C, Allen P (2002) Multiple regions of RyR1 mediate functional and structural interactions with $\alpha 1$ s-dihidropyridine receptors in skeletal muscle. Biophys J 83:3220-3244

Putney J Jr (1986) A model for receptor-regulated calcium entry. Cell Calcium 7:1-12

Racay P, Gregory P, Schwaller B (2006) Parvalbumin deficiency in fasttwitch muscles leads to increased 'slow-twitch type' mitochondria, but does not affect the expression of fiber specific proteins. FEBS J 273:96-108

Raju B, Murphy E, Levy L, Hall R, London R (1989) A fluorescent indicator for measuring cytosolic free magnesium. Am J Physiol 256:C540-C548

Ramesh V, Sharma V, Sheu S, Franzini-Armstrong C (1998) Structural proximity of mitochondria to calcium release units in rat ventricular myocardium may suggest a role in $\mathrm{Ca} 2+$ sequestration. Ann N Y Acad Sci 853:341-344

Rando T, Blau H (1994) Primary mouse myoblast purification, characterization and transplantation for cell-mediated gene therapy. J Cell Biol 125:1275-1287 
Ranvier L (1873) Propriétés et structures différentes des muscles rouges et des muscles blancs, chez les Lapins et chez les Raies. Compt Rendus 77:1030-1034

Rapizzi E, Pinton P, Szabadkai G, Wieckowski M, Vandecasteele G, Baird G, Tuft R, Fogarty K, Rizzuto R (2002) Recombinant expression of the voltage-dependent anion channel enhances the transfer of Ca2+ microdomains to mitochondria. J Cell Biol 159:613-624

Rausch M, Treves S, Zorzato F (2013) 3D Structural illumination microscopy of the skeletal muscle excitation-contraction coupling macromolecular complex. Biophys J 104(2-S1):105a. abstract, 544-Pos

Reardon T, Allen D (2009) Time to fatigue is increased in mouse muscle at $37^{\circ} \mathrm{C}$; the role of iron and reactive oxygen species. J Physiol 587: 4705-4716

Rebbeck R, Willemse H, Groom L, Dirksen R, Dulhunty A (2013) Interactions between dihydropyridine $\beta 1 \mathrm{~A}$ subunit and ryanodine receptor isoforms. Biophys J 104(2-S1):105a. abstract,543-Pos

Reggiani C, te Kronnie T (2006) RyR isoforms and fibre-type specific expression of proteins controlling intracellular calcium concentration in skeletal muscles. J Muscle Res Cell Motil 27:327-335

Reid M (2001) Plasticity in Skeletal, Cardiac, and Smooth Muscle. Invited Review: Redox modulation of skeletal muscle contraction: what we know and what we don't. J Appl Physiol 90:724-731

Reid M, Haack K, Kathleen F, Valberg P, Kobzik L, West S (1992) Reactive oxygen in skeletal muscle. I. Intracellular oxidant kinetics and fatigue in vitro. J Appl Physiol 73:1797-1804

Ridgway E, Ashley C (1967) Calcium transients in single muscle fibres. Biochem Biophys Res Commun 29:229-234

Ríos E, Brum G (1987) Involvement of dihydropyridine receptors in excitation-contraction coupling in skeletal muscle. Nature 325:717-720

Ríos E, Pizarro G (1988) Voltage sensors and calcium channels of excitation-contraction coupling. News Physiol Sci 3:223-227

Ríos E, Pizarro G (1991) Voltage sensor of excitation-contraction coupling in skeletal muscle. Physiol Rev 71:849-908

Ríos E, Karhanek M, Ma J, González A (1993) An Allosteric model of the molecular interactions of excitation-contraction coupling in skeletal muscle. J Gen Physiol 102:449-481

Rizzuto R, Pozzan T (2006) Microdomains of intracellular Ca2+: molecular determinants and functional consequences. Physiol Rev 86: 369-408

Rizzuto R, Simpson AW, Brini M, Pozzan T (1992) Rapid changes of mitochondrial $\mathrm{Ca} 2+$ revealed by specifically targeted recombinant aequorin. Nature 358:325-327

Rizzuto R, Brini M, Murgia M, Pozzan T (1993) Microdomains with high $\mathrm{Ca} 2+$ close to IP3-sensitive channels that are sensed by neighboring mitochondria. Science 262:744-747

Rizzuto R, Pinton P, Carrington W, Fay FS, Fogarty KE, Lifshitz LM, Tuft R, Pozzan T (1998) Close contacts with the endoplasmic reticulum as determinants of mitochondrial $\mathrm{Ca} 2+$ responses. Science 280:1763-1766

Rizzuto R, Bernardi P, Pozzan T (2000) Mitochondria as all-round players of the calcium game. J Physiol 529:37-47

Rizzuto R, Marchi S, Bonora M, Aguiari P, Bononi A, De Stefani D, Giorgi C, Leo S, Rimessi A, Siviero R, Zecchini E, Pinton P (2009) $\mathrm{Ca}(2+)$ transfer from the ER to mitochondria: when, how and why. Biochim Biophys Acta 1787:1342-1351

Rogers K, Picaud S, Roncali E, Boisgard R, Colasante C, Stinnakre J, Tavitian B, Brulet P (2007) Non-invasive in vivo imaging of calcium signaling in mice. PLoS One 2:e974

Roos J, DiGregorio PJ, Yeromin AV, Ohlsen K, Lioudyno M, Zhang S, Safrina O, Kozak JA, Wagner SL, Cahalan MD, Velicelebi G, Stauderman K (2005) STIM1, an essential and conserved component of store-operated Ca2 + channel function. J Cell Biol 169:435-445

Rossi R, Bottinelli R, Sorrentino V, Reggiani C (2001) Response to caffeine and ryanodine receptor isoforms in mouse skeletal muscle. Am J Physiol Cell Physiol 281:C585-C594
Rossi A, Boncompagni S, Wei L, Protasi F, Dirksen R (2011) Differential impact of mitochondrial positioning on mitochondrial $\mathrm{Ca}(2+)$ uptake and $\mathrm{Ca}(2+)$ spark suppression in skeletal muscle. Am J Physiol Cell Physiol 301:C1128-C1139

Rousseau E, Pinkos J (1990) pH modulates conducting and gating behaviour of single calcium release channels. Pflugers Arch 415:645-657

Royer L, Sztretye M, Manno C, Pouvreau S, Zhou J, Knollmann B, Protasi F, Allen P, Rios E (2010) Paradoxical buffering of calcium by calsequestrin demonstrated for the calcium store of skeletal muscle. J Gen Physiol 136:325-338

Rudolf R, Mongillo M, Magalhaes P, Pozzan T (2004) In vivo monitoring of $\mathrm{Ca}^{2+}$ uptake into mitochondria of mouse skeletal muscle during contraction. J Cell Biol 166:527-536

Ryu S, Beutner G, Dirksen R, Kinnally K, Sheu S (2010) Mitochondrial ryanodine receptors and other mitochondrial $\mathrm{Ca} 2+$ permeable channels. FEBS Lett 584:1948-1955

Ryu S, Beutner G, Kinnally K, Dirksen R, Sheu S (2011) Single channel characterization of the mitochondrial ryanodine receptor in heart mitoplasts. J Biol Chem 286:21324-21329

Samsó M, Wagenknecht T, Allen D (2005) Internal structure and visualization of transmembrane domains of the RyR1 calcium release channel by cryo-EM. Nat Struct Mol Biol 12:539-544

Samsó M, Feng W, Pessah I, Allen P (2009) Coordinated movement of cytoplasmic and transmembrane domains of RyR1 upon gating. PLoS Biol 7:e85

Sandow A (1952) Excitation-contraction coupling in muscular response. Yale J Biol Med XXV:176-201. In his classical review article Professor Sandow coined the term "Excitation-Contraction Coupling" to define the chain of events that starting with the action potential, ended with force development, at a time when the nature of all the intermediate events was unknown, indicating the way for future research. The term has become so popular that it is used even in the absence of excitation as when caffeine is used to induce contraction, or to describe another phenomenon, as when the term "Excitation-Secretion Coupling"is used

Sandow A (1964) Potentiation of muscular contraction. Arch Phys Med Rehabil 45:62-81

Sandow A (1965) Excitation-Contraction Coupling in skeletal muscle. Pharmacol Rev 17:265-320

Sandow A, Isaacson A (1966) Topochemical factors in potentiation of contraction by heavy metal cations. J Gen Physiol 49:937-961

Sandow A, Taylor S, Preiser H (1965) Role of the action potential in excitation-contraction coupling. Fed Proc 24:1116-1123

Santo-Domingo J, Demaurex N (2010) Calcium uptake mechanisms of mitochondria. Biochim Biophys Acta 1797:907-912

Saris N, Carafoli E (2005) A historical review of cellular calcium handling, with emphasis on mitochondria. Biochemistry (Mosc) 70: $187-194$

Schein S, Colombini M, Finkelstein A (1976) Reconstitution in planar lipid bilayers of a voltage-dependent anion-selective channel obtained from paramecium mitochondria. J Membr Biol 30:99-120

Schermelleh L, Heintzmann R, Leonhardt H (2010) A guide to superresolution fluorescence microscopy. J Cell Biol 190:165-175

Schiaffino S, Gorza L, Sartore S, Saggin L, Ausoni S, Vianello M, Gundersen K, Lømo T (1989) Three myosin heavy chain isoforms in type 2 skeletal muscle fibres. J Muscle Res Cell Motil 10:197-205

Schmitt T, Pette D (1991) Fiber type-specific distribution of parvalbumin in rabbit skeletal muscle. Histochemistry 96:459-465

Schneider M, Chandler W (1973) Voltage dependent charge movement in skeletal muscle: a possible step in excitation-contraction coupling. Nature 242:244-246

Scriven D, Tafteh R, Chou K, Moore E (2013) Super-resolution localization and distribution of proteins within the mammalian couplon. Biophys J 104(2-S1):105a. abstract,545-Pos

Sembrowich W, Quintinskie J, Li G (1985) Calcium uptake in mitochondria from different skeletal muscle types. J Appl Physiol 59:137-141 
Sen C (1995) Oxidants and antioxidants in exercise. J Appl Physiol 79: 675-686

Serysheva I, Chiu W, Ludtke S (2007) Single-particle electron cryomicroscopy of the ion channels in the excitation-contraction coupling junction. Methods Cell Biol 79:407-435

Shaw M, Ostap E, Goldman Y (2003) Mechanism of inhibition of skeletal muscle actomyosin by N-benzyl-p-toluene sulphonamide. Biochemistry 42:6128-6135

Shirokova N, Ríos E (1997) Small event Ca2+ release: a probable precursor of Ca2 + sparks in frog skeletal muscle. J Physiol 502:3-11

Shirokova N, García J, Pizarro G, Ríos E (1996) $\mathrm{Ca}^{2+}$ release from the sarcoplasmic reticulum compared in amphibian and mammalian skeletal muscle. J Gen Physiol 107:1-18

Shkryl V, Shirokova N (2006) Transfer and tunneling of $\mathrm{Ca}^{2+}$ from sarcoplasmic reticulum to mitochondria in skeletal muscle. J Biol Chem 281:1547-1554

Shore G, Tata J (1977) Two fractions of rough endoplasmic reticulum from rat liver. I. Recovery of rapidly sedimenting endoplasmic reticulum in association with mitochondria. J Cell Biol 72:714-725

Shtifman A, Ward C, Wang J, Valdivia H, Schneider M (2000) Effects of imperatoxin $\mathrm{A}$ on local sarcoplasmic reticulum $\mathrm{Ca}(2+)$ release in frog skeletal muscle. Biophys J 79:814-827

Smets I, Caplanusi A, Despa S, Molnar Z, Radu M, VandeVen M, Ameloot M, Steels P (2004) Ca2+ uptake in mitochondria occurs via the reverse action of the $\mathrm{Na}+/ \mathrm{Ca} 2+$ exchanger in metabolically inhibited MDCK cells. Am J Physiol Ren Physiol 286:F784-F794

Smith J, Imagawa T, Ma J, Fill M, Campbell K, Coronado R (1988) Purified ryanodine receptor from rabbit skeletal muscle is the $\mathrm{Ca}^{2+}$ release channel of the SR. J Gen Physiol 92:1-26

Smyth J, Dehaven W, Jones B, Mercer J, Trebak M, Vazquez G, Putney J $\mathrm{Jr}$ (2006) Emerging perspectives in store-operated Ca2+ entry: roles of Orai, Stim and TRP. Biochim Biophys Acta 1763:1147-1160

Soboloff J, Spassova M, Dziadek M, Gill D (2006) Calcium signals mediated by STIM and Orai proteins-a new paradigm in interorganelle communication. Biochim Biophys Acta 1763:1161-1168

Sparagna G, Gunter K, Sheu S, Gunter T (1995) Mitochondrial calcium uptake from physiological-type pulses of calcium. A description of the rapid uptake mode. J Biol Chem 270:27510-27515

Stern M (1992) Buffering of calcium in the vicinity of a channel pore. Cell Calcium 13:183-192

Stiber J, Hawkins A, Zhang Z, Wang S, Burch J, Graham V, Ward C, Seth M, Finch E, Malouf N, Williams R, Eu J, Rosenberg P (2008) STIM1 signalling controls store-operated calcium entry required for development and contractile function in skeletal muscle. Nat Cell Biol 10:688-697

Sun Y, Lou F, Edman K (2001) 2,3-Butanedione monoxime increases speed of relaxation in single muscle fibres of frog. Acta Physiol Scand 172:53-61

Szentesi P, Jacquemond V, Kovács L, Csernoch L (1997) Intramembrane charge movement and sarcoplasmic calcium release in enzymatically isolated mammalian skeletal muscle fibres. J Physiol 502:371-384

Takahashi A, Camacho P, Lechleiter J, Herman B (1999) Measurement of intracellular calcium. Physiol Rev 79:1089-1125

Takehura H, Fujinami N, Nishizawa T, Ogasawara H, Kasuga N (2001) Eccentric exercise-induced morphological changes in the membrane systems involved in excitation-contraction coupling in rat skeletal muscle. J Physiol 533:571-583

Takeshima H, Nishimura S, Matsumoto T, Ishida H, Kangawa K, Minamino N, Matsuo H, Ueda M, Hanaoka M, Hirose T et al (1989) Primary structure and expression from complementary DNA of skeletal muscle ryanodine receptor. Nature 339:439445

Tanabe T, Takeshima H, Mikami A, Flockerzi V, Takahashi H, Kangawa K, Kojima M, Matsuo H, Hirose T, Numa S (1987) Primary structure of the receptor for calcium channel blockers from skeletal muscle. Nature 328:313-318
Tanabe T, Beam K, Powell J, Numa S (1988) Restoration of excitationcontraction coupling and slow calcium current in dysgenic muscle by dihydropyridine receptor complementary DNA. Nature 336:134-139

Tanabe T, Beam K, Adams B, Niidome T, Numa S (1990) Regions of the skeletal dihydropyridine receptor critical for excitation-contraction coupling. Nature 346:567-569

Tang S, Wong H, Wang Z, Huang Y, Zhuo Y, Pennati A, Gadda G, Delbono O, Yang J (2011) Design and application of a class of sensors to monitor $\mathrm{Ca} 2+$ dynamics in high $\mathrm{Ca} 2+$ concentration cellular compartments. Proc Natl Acad Sci U S A 108:16265-16270

Toyoshima H, Mizutani T (2004) Crystal structure of the calcium pump with a bound ATP analogue. Nature 430:529-535

Treves S, Vukcevic M, Maj M, Thurnheer R, Mosca B, Zorzato F (2009) Minor sarcoplasmic reticulum membrane components that modulate excitation-contraction coupling in striated muscles. J Physiol 587: 3071-3079

Treves S, Thurnheer R, Mosca B, Vukcevic M, Bergamelli L, Voltan R, Oberhauser V, Ronjat M, Csernoch L, Szentesi P, Zorzato F (2012) SRP-35, a newly identified protein of the skeletal muscle sarcoplasmic reticulum, is a retinol dehydrogenase. Biochem J 441:731-741

Tsien R (1981) A non-disruptive technique for loading calcium buffers and indicators into cells. Nature 290:527-528

Tsugorka A, Ríos E, Blatter L (1995) Imaging elementary events of calcium release in skeletal muscle cells. Science 269:1723-1726

Tung C, Lobo P, Kimlicka L, Van Petegem F (2010) The amino-terminal disease hotspot of ryanodine receptors forms a cytoplasmic vestibule. Nature 468:585-58

Tupling R (2004) The sarcoplasmic reticulum in muscle fatigue and disease: role of the sarco(endo)plasmic reticulum Ca2+-ATPase. Can J Appl Physiol 29:308-329

van der Poel C, Edwards J, Macdonald W, Stephenson D (2008) Effect of temperature-induced reactive oxygen species production on excitation-contraction coupling in mammalian skeletal muscle. Clin Exp Pharmacol Physiol 35:1482-1487

Vendelin M, Beraud N, Guerrero K, Andrienko T, Kuznetsov A, Olivares J, Kay L, Saks V (2005) Mitochondrial regular arrangement in muscle cells: a "crystal-like" pattern. Am J Physiol Cell Physiol 288:C757-C767

Verburg E, Murphy R, Stephenson G, Lamb G (2005) Disruption of excitation-contraction coupling and titin by endogenous $\mathrm{Ca} 2+$-activated proteases in toad muscle fibres. J Physiol 564:775-789

Verburg E, Dutka T, Lamb G (2006) Long-lasting muscle fatigue: partial disruption of excitation-contraction coupling by elevated cytosolic $\mathrm{Ca}^{2+}$ concentration during contractions. Am J Physiol 290:C1199 $\mathrm{C} 1208$

Vig M, Peinelt C, Beck A, Koomoa DL, Rabah D, Koblan-Huberson M, Kraft S, Turner H, Fleig A, Penner R, Kinet J (2006) CRACM1 is a plasma membrane protein essential for store-operated $\mathrm{Ca} 2+$ entry. Science 312:1220-1223

Vig M, DeHaven W, Bird G, Billingsley J, Wang H, Rao P, Hutchings A, Jouvin M, Putney J, Kinet J (2008) Defective mast cell effector functions in mice lacking the CRACM1 pore subunit of store-operated calcium release-activated calcium channels. Nat Immunol 9:89-96

Wagenknecht T, Grassucci R, Frank J, Saito A, Inui M, Fleischer S (1989) Three-dimensional architecture of the calcium channel/foot structure of sarcoplasmic reticulum. Nature 338:167-170

Wagenknecht T, Hsieh C-E, Rath B, Fleischer S, Marko M (2002) Electron tomography of frozen-hydrated isolated triad junctions. Biophys J 83:2491-2501

Wang Z, Zheng Z, Messi M, Delbono O (2007) Muscle fibers from senescent mice retain excitation-contraction coupling properties in culture. In vitro Cell Dev Biol 43:222-234

Wang Z, Tang S, Messi M, Yang J, Delbono (2012) Residual sarcoplasmic reticulum $\mathrm{Ca} 2+$ concentration after $\mathrm{Ca} 2+$ release in skeletal myofibers from young adult and old mice. Pflugers Arch 463: 615-624 
Ward C, Prosser B, Greiser M, Westerblad H, Khairallah R, Lederer W (2011) A novel assay of mechano-transduction in single muscle cells. Biophys J 100:589a. abstract,3185-Pos

Weber A (1959) On the role of calcium in the activity of adenosine 5'triphosphate hydrolysis by actomyosin. J Biol Chem 234:2764 2769

Weber A, Herz R (1968) The relationship between caffeine contracture in intact muscle and the effect of caffeine on Reticulum. J Gen Physiol 52:750-759

Wei L, Varsányi M, Dulhunty A, Beard N (2006) The conformation of calsequestrin determines its ability to regulate skeletal ryanodine receptors. Biophys J 91:1288-1301

Weisleder N, Zhou J, Ma J (2012) Detection of calcium sparks in intact and permeabilized skeletal muscle fibers. Methods Mol Biol 798: 395-410

Westerblad H (1999) The role of $\mathrm{pH}$ and inorganic phosphate ions in skeletal muscle fatigue. Chapter 12. In: Hargreaves M, Thompson M (eds) Biochemistry of exercise X. Champaign, USA, Human Kinetics, pp p147-p154

Westerblad H, Allen D (1991) Changes of myoplasmic calcium concentration during fatigue in single mouse muscle fibers. J Gen Physiol 98:615-635

Westerblad H, Allen D (1992) Myoplasmic free $\mathrm{Mg}^{2+}$ concentration during repetitive stimulation of single fibres from mouse skeletal muscle. J Physiol 453:413-434

Westerblad H, Allen D (1993) The contribution of $\left[\mathrm{Ca}^{2+}\right]_{\mathrm{i}}$ to the slowing of relaxation in fatigued single fibres from mouse skeletal muscle. $\mathrm{J}$ Physiol 468:729-740

Westerblad H, Lännergren J (1991) Slowing of relaxation during fatigue in single mouse muscle fibres. J Physiol 434:323-336

Westerblad H, Allen D, Lännergren J (2002) Muscle fatigue: lactic acid or inorganic phosphate the major cause? News Physiol Sci 17:17-21

Williams D, Head S, Bakker A, Stephenson G (1990) Resting calcium concentrations in isolated skeletal muscle fibres of dystrophic mice. J Physiol 428:243-256

Winegrad S (1968) Intracellular calcium movements of frog skeletal muscle during recovery from tetanus. J Gen Physiol 51:65-83

Wium E, Dulhunty A, Beard N (2012) A skeletal muscle ryanodine receptor interaction domain in triadin. PLoS One 7:e43817
Wong J, Baddeley D, Bushong E, Yu Z, Ellisman M, Hoshijima M, Soeller C (2013) Nanoscale distribution of ryanodine receptors and caveolin-3 in mouse ventricular myocytes: dilation of T-tubules near the junctions. Biophys J 104:L22-L24

Wood D, Zollman J, Reuben J (1975) Human skeletal muscle properties of the "chemically skinned" fiber. Science 187:1075-1076

Woods C, Novo D, DiFranco M, Vergara J (2004) The action potentialevoked sarcoplasmic reticulum calcium release is impaired in $\mathrm{mdx}$ mouse muscle fibres. J Physiol 557:59-75

Yaffe D, Saxel O (1977) Serial passaging and differentiation of myogenic cells isolated from dystrophic mouse muscle. Nature 270:725-727

Yi J, Ma C, Li Y, Weisleder N, Rios E, Ma J, Zhou J (2011) Mitochondrial calcium uptake regulates rapid calcium transients in skeletal muscle during excitation-contraction (E-C) coupling. J Biol Chem 286: 32436-32443

Zalman L, Nikaido H, Kagawa Y (1980) Mitochondrial outer membrane contains a protein producing nonspecific diffusion channels. J Biol Chem 255:1771-1774

Zhang S, Yu Y, Roos J, Kozak J, Deerinck T, Ellisman M, Stauderman K, Cahalan M (2005) STIM1 is a Ca2+ sensor that activates CRAC channels and migrates from the $\mathrm{Ca} 2+$ store to the plasma membrane. Nature 437:902-905

Zhou J, Launikonis B, Ríos E, Brum G (2004) Regulation of Ca2+ sparks by $\mathrm{Ca} 2+$ and $\mathrm{Mg} 2+$ in mammalian and amphibian muscle. An RyR isoform-specific role in excitation-contraction coupling? J Gen Physiol 124:409-428

Zhou J, Yi J, Royer L, Launikonis B, González A, García J, Ríos E (2006) A probable role of dihydropyridine receptors in repression of $\mathrm{Ca} 2+$ sparks demonstrated in cultured mammalian muscle. Am J Physiol Cell Physiol 290:C539-C553

Zoratti M, Szabo I, De Marchi U (2005) Mitochondrial permeability transitions: how many doors to the house? Biochim Biophys Acta 1706:40-52

Zorzato F, Fujii J, Otsu M, Phillips M, Green N, Lai F, Meissner G, MacLennan D (1990) Molecular cloning of cDNA encoding human and rabbit forms of the $\mathrm{Ca}^{2+}$ release channel (ryanodine receptor) of skeletal muscle sarcoplasmic reticulum. J Biol Chem 265:22442256 